\title{
Determining the presence of asthma- related molecules and salivary contamination in exhaled breath condensate
}

Charmion Cruickshank-Quinn, Michael Armstrong, Roger Powell, Joe Gomez, Marc Elie and Nichole Reisdorph*

\begin{abstract}
Background: Researchers investigating lung diseases, such as asthma, have questioned whether certain compounds previously reported in exhaled breath condensate $(E B C)$ originate from saliva contamination. Moreover, despite its increasing use in 'omics profiling studies, the constituents of EBC remain largely uncharacterized. The present study aims to define the usefulness of EBC in investigating lung disease by comparing EBC, saliva, and saliva-contaminated EBC using targeted and untargeted mass spectrometry and the potential of metabolite loss from adsorption to EBC sample collection tubes.
\end{abstract}

Methods: Liquid chromatography mass spectrometry (LC-MS) was used to analyze samples from 133 individuals from three different cohorts. Levels of amino acids and eicosanoids, two classes of molecules previously reported in EBC and saliva, were measured using targeted LC-MS. Cohort 1 was used to examine contamination of EBC by saliva. Samples from Cohort 1 consisted of clean EBC, saliva-contaminated EBC, and clean saliva from 13 healthy volunteers; samples were analyzed using untargeted LC-MS. Cohort 2 was used to compare eicosanoid levels from matched EBC and saliva collected from 107 asthmatic subjects. Samples were analyzed using both targeted and untargeted LC-MS. Cohort 3 samples consisted of clean-EBC collected from 13 subjects, including smokers and non-smokers, and were used to independently confirm findings; samples were analyzed using targeted LC-MS, untargeted LC-MS, and proteomics. In addition to human samples, an in-house developed nebulizing system was used to determine the potential for EBC samples to be contaminated by saliva.

Results: Out of the 400 metabolites detected in both EBC and saliva, 77 were specific to EBC; however, EBC samples were concentrated 20 -fold to achieve this level of sensitivity. Amino acid concentrations ranged from $196 \mathrm{pg} / \mathrm{mL}-4 \mu \mathrm{g} / \mathrm{mL}$ (clean EBC), $1.98 \mathrm{ng} / \mathrm{mL}-6 \mu \mathrm{g} / \mathrm{mL}$ (saliva-contaminated EBC), and $13.84 \mathrm{ng} / \mathrm{mL}-1256 \mathrm{mg} / \mathrm{mL}$ (saliva). Eicosanoid concentration ranges were an order of magnitude lower; $10 \mathrm{pg} / \mathrm{mL}-76.5 \mathrm{ng} / \mathrm{mL}$ (clean EBC), $10 \mathrm{pg} / \mathrm{mL}-898 \mathrm{ng} / \mathrm{mL}$ (saliva-contaminated EBC), and $2.54 \mathrm{ng} / \mathrm{mL}-272.9 \mathrm{mg} / \mathrm{mL}$ (saliva). Although the sample size of the replication cohort (Cohort 3) did not allow for statistical comparisons, two proteins and 19 eicosanoids were detected in smoker vs. non-smoker clean-EBC.

Conclusions: We conclude that metabolites are present and detectable in EBC using LC-MS; however, a large starting volume of sample is required.

Keywords: EBC, Saliva, Lung, Metabolomics, Proteomics, LC-MS, Amino acids, Eicosanoids, Leukotriene, Asthma

\footnotetext{
* Correspondence: Nichole.Reisdorph@UCDenver.edu

Skaggs School of Pharmacy and Pharmaceutical Sciences, University of

Colorado Anschutz Medical Campus, 12850 East Montview Boulevard, Aurora,

CO 80045-2605, USA
} 


\section{Background}

Exhaled breath condensate (EBC) is comprised of volatile gases (e.g. nitric oxide) [1] and non-volatile compounds such as eicosanoids and cytokines [2]. EBC is increasingly used as a tool for biomarker discovery; it can be obtained non-invasively and reflects the physiology of the airway lining, thereby providing vital information about lung health. Publications have reported on the benefits of EBC as a quick screening tool for lung diseases such as asthma [3-6], pneumonia [5], chronic obstructive pulmonary disease (COPD) [5-8], cystic fibrosis $[4,9,10]$, and pneumoconiosis [11]; these suggest the potential for EBC to be used in point-of-care diagnostics.

Several EBC studies have focused on eicosanoids due to their known relationship to lung disease and the fact that these compounds are released from mast cells and eosinophils during inflammatory responses [12]. Leukotriene B4 $\left(\mathrm{LTB}_{4}\right)$, for example, has been shown to be released by activated alveolar macrophages in sarcoidosis patients [13]. Moreover, levels of cysteinyl-leukotrienes (CysLT) and 8-isoprostane have been reported to be increased in EBC of moderate and severe asthma patients compared to healthy controls [14]. Antczek et al. [15] investigated CysLT, $\mathrm{LTB}_{4}$, prostaglandin $\mathrm{E} 4\left(\mathrm{PGE}_{4}\right)$, and 8-isoprostane in longitudinal EBC samples of 16 COPD patients at 4 time points: day 1 , during treatment, after therapy, and when stable. Their results showed (1) a decrease in CysLT, $\mathrm{LTB}_{4}$, and 8-isoprostane after antibiotic therapy and (2) that eicosanoids were elevated in the airways of stable COPD patients compared to healthy subjects. Although numerous studies demonstrate the potential for EBC in point-of-care diagnostics, eicosanoid detection in EBC can be marked by loss of analyte due to adsorption in plastic collection tubes. Therefore, recent investigators have examined the use of glass tubes coated with surfactants, such as Tween 20, as an alternative to improve eicosanoid analysis in EBC [16].

In addition to eicosanoids, other EBC studies have focused on the measurement of nitrogen oxide [17], glucose [10], proteins [18], and amino acids [19]. Amino acids have been shown to be markers of lung function [20], are dysregulated in COPD [21, 22], and are perturbed in smokers [23]. Although amino acids and eicosanoids have been reported in EBC [19, 24, 25], the contribution from saliva remains in question. Saliva contains more than 200 metabolites [26, 27] and has been suggested as a source of contamination in EBC during sample collection. Of the EBC collection devices commercially available, only two (ECoScreen, and TURBO-DECCS) contain saliva traps [28].

Because there is potential for saliva contamination in $\mathrm{EBC}$, many investigators test for saliva contamination by measuring hydrolytic $\alpha$-amylase activity. Syslova et al [29] investigated CysLTs using a rapid method comprising pre-concentration, stable isotope dilution, and immunoaffinity. Since the $\alpha$-amylase activity in samples did not exceed $0.1 \%$ of the saliva activity, the investigators excluded significant salivary contamination of EBC. However, small amounts of saliva molecules can be detected by liquid chromatography tandem mass spectrometry (LC-MS/MS); Gaber et al reported that the main source of $\mathrm{LTB}_{4}$ detected in EBC was from saliva [25]. $\mathrm{LTB}_{4}$ and $\alpha$-amylase activity were measured in saliva and $\alpha$-amylase activity was measured in undiluted EBC. The authors observed that spiking EBC with saliva consistently increased $\mathrm{LTB}_{4}$ levels in EBC and concluded that $\alpha$ amylase assay may not be sufficiently sensitive to show the presence of saliva in small quantities.

We sought to define the usefulness of EBC in investigating lung disease by characterizing its constituents and delineating if the molecules reportedly detected in EBC are a result of saliva contamination during sample collection. This was achieved using three strategies. First, we used an in-house developed nebulizing system to validate methods and to determine loss of molecules during collection. Second, since they have been reported as increased in lung disease, we specifically measured amino acids and eicosanoids in saliva and EBC in both healthy and asthmatic individuals. Finally, we used untargeted metabolomics and proteomics to determine the components of a highly concentrated EBC sample.

\section{Methods}

\section{Study population}

Adults were recruited from asthmatic patients at National Jewish Health through flyers and through the asthma clinic. Studies were approved by the Western Institutional Review Board or National Jewish Health IRB. Informed consent was obtained from all participants. The 133 volunteers were adult males and females ranging in age 27-64 years old; subjects filled out questionnaires detailing the last time they ate, drank, brushed their teeth, flossed, or used mouthwash.

Cohort 1: This cohort included 13 healthy subjects with no pre-existing conditions who provided clean-EBC, saliva-EBC, and/or clean saliva. Not all subjects were able to provide both EBC and saliva: $80 \%$ of subjects who provided clean-EBC provided saliva; $100 \%$ of subjects who provided saliva-EBC also provided saliva; 5 subjects who provided saliva did not provide EBC.

Cohort 2: This cohort consists of 107 asthmatic subjects who had matched saliva and EBC collected. One subject who provided EBC did not provide saliva.

Cohort 3: This cohort refers to a separate group of 13 subjects of various health statuses - healthy smoker, healthy non-smoker, common cold, nasal congestion who all provided clean-EBC. The smoker group is designated as smoking at least one cigarette per day, while healthy indicated no other pre-existing conditions. 
Additional demographic data is unavailable for the cohorts as patient samples were de-identified and additional information was no longer available following completion of the study. Because only minimal information was available, no statistical claims are being made based on health status, gender, or age in these cohorts.

\section{Chemicals and reagents}

All solvents for untargeted mass spectrometry were LCMS grade. Acetonitrile, methanol, and formic acid were purchased from Fisher Scientific (Fairlawn, New Jersey); Water was purchased from Honeywell (Muskegon Michigan); 1-methylhistidine, 3-methylhistidine, $\alpha$-aminon-butyric acid, alanine, anserine, arginine, asparagine, aspartic acid, $\beta$-aminoisobutryic acid, $\beta$-alanine, carnosine, citrulline, creatinine, cystathionine, cysteine, ethanolamine, $\gamma$-aminobutyric acid, glutamic acid, glutamine, glycine, histidine, homocystine, hydroxylysine, hydroxyproline, isoleucine, L-aminoadipic acid, L-cystine, leucine, lysine, proline, methionine, ornithine, phenylalanine, phosphoserine, phosphoethanolamine, sarcosine, serine, taurine, threonine, tryptophan, tyrosine, urea, and valine were purchased from Sigma Aldrich (St. Louis, Missouri); 10(S),17(S)-DiHDoHE (Protectin DX), 11ß-PGF $\mathrm{PF}_{2 \alpha}, 14(\mathrm{~S})-$ HDHA, 15R-PGF $2 \alpha$, 17(S)-HDHA, 8-iso-15R-PGF $2 \alpha$, 8-iso-PGF $\mathrm{PG}_{2 \alpha}$ Lipoxin A4 $\left(\mathrm{LXA}_{4}\right), \mathrm{LTB}_{4}, \mathrm{LTC}_{4}, \mathrm{LTD}_{4}$, $\mathrm{LTE}_{4}, \mathrm{PGE}_{2}, \mathrm{PGF}_{2 \alpha}$, Resolvin D1 (RVD1), and Resolvin D2 (RVD2) were purchased from Cayman Chemical (Ann Arbor, Michigan).

All standards and deuterated internal standards used for LC-MS/MS analysis of arachidonic acid, docosahexaenoic acid derived lipid mediators were purchased from Cayman Chemical (Ann Arbor, Michigan, USA). All HPLC solvents and extraction solvents were HPLC grade or better.

\section{EBC spike recovery experiments: evaluation of adsorption to glass versus plastic tubes}

To evaluate adsorption of eicosanoids during collection and analysis, simulated experiments were conducted with different types of collection tubes and analysis was performed with two EBC devices to determine compound adsorption to these different tubes. Glass and plastic collection tubes were tested with the RTube device (a disposable collection system which separates saliva from the exhaled breath) (Respiratory Research, Inc., Charlottesville, VA). Glass with polyethylene terephthalate (PET), glass without PET and plastic without PET were tested with the TURBO DECCS device (a transportable unit for use in research on biomarkers obtained from disposable exhaled condensate collection systems) (Medivac, Italy). EBC production and deposition was simulated using the EBC sampling devices without human subjects.

\section{RTube EBC simulation standards}

The deuterated internal standard solution contained $\mathrm{LTB}_{4}-\mathrm{d} 4, \mathrm{LTE}_{4}-\mathrm{d} 3$ and $\mathrm{PGE}_{2}-\mathrm{d} 4$ at concentrations of $500 \mathrm{pg} / \mathrm{ml}$ in ethanol and stored at $-20{ }^{\circ} \mathrm{C}$ until use. The calibration standards $\left(\mathrm{LTB}_{4}, \mathrm{LTC}_{4}, \mathrm{LTD}_{4}\right.$, and $\left.\mathrm{LTE}_{4}\right)$ were prepared in LC-MS water to final concentrations of $5,10,25,50,100$, and $250 \mathrm{pg} / \mathrm{mL}$ and they were kept on ice until use. Standards were prepared for analysis by adding $200 \mu \mathrm{L}$ of deuterated internal standard solution and $800 \mu \mathrm{L}$ of calibration standard into a $2 \mathrm{~mL}$ autosampler vial and vortexing for $5 \mathrm{~s}$. The $10 \mathrm{pg} / \mathrm{mL}$ (low level) and $100 \mathrm{pg} / \mathrm{mL}$ (high level) calibration standards were used for infusion in the EBC simulation experiment.

\section{RTube EBC simulation setup}

The RTube was constructed with an alternative material (Borosilicate glass) and the performance compared with the plastic RTube. The EBC simulation apparatus utilized the following components: syringe pump, a plastic $10 \mathrm{~mL}$ luer lock BD syringe, a 2 foot section of $0.17 \mathrm{~mm}$ PEEK tubing with an inline $2 \mu \mathrm{m}$ frit and luer lock adapter, an Agilent electrospray nebulizer and column stand, nitrogen (98\% pure or better) supplied at 10psi, an aluminum condenser (for plastic RTubes) stored at $-80{ }^{\circ} \mathrm{C}$, and water ice condenser fabricated with a zip-lock bag (for glass RTubes) stored at $-80^{\circ} \mathrm{C}$.

Before each simulation, the syringe, tubing and nebulizer assembly was rinsed with $200 \mu \mathrm{L}$ of LC-MS methanol. 8-9 $\mathrm{mL}$ of low or high level standard was poured into the $10 \mathrm{~mL}$ syringe and placed into the syringe pump. The syringe was attached to the tubing and nebulizer. The gas port of the nebulizer was blocked with a blank nut. The syringe pump was set to pump $1.5 \mathrm{~mL}$ of standard solution for $5 \mathrm{~min}(0.3 \mathrm{~mL} / \mathrm{min})$. A first $5 \mathrm{~min}$ infusion was run and discarded to purge the line; a second 5 min infusion was run and collected in a $2 \mathrm{~mL}$ glass autosampler vial as a control sample. Nitrogen at 10 psi was then attached to the nebulizer. The syringe pump was operated for $20 \mathrm{~s}$ to observe and verify the nebulizer spray quality. A glass or plastic RTube was attached to the column stand. The nebulizer was then attached to the column stand with the nebulizer tip protruding 1-5 mm above the RTube duckbill.

The appropriate condenser was slid over the RTube and careful observation was made to ensure that the nebulizer needle was centered in the duckbill. The syringe pump was allowed to flow for $5 \mathrm{~min}$. The glass RTube required a small amount of isopropanol $(20-50 \mu \mathrm{L})$ to be injected with a spinal needle between the bottom of the duckbill and the walls of the condenser to prevent the duckbill from sticking to the walls during the EBC recovery. Condensate was aliquoted into a $2 \mathrm{~mL}$ glass autosampler vial and placed on ice. Samples were prepared for analysis by adding $800 \mu \mathrm{L}$ of condensate and $200 \mu \mathrm{L}$ of deuterated 
internal standard to a $2 \mathrm{~mL}$ glass autosampler vial and vortexing for $5 \mathrm{~s}$.

\section{TURBO DECCS EBC simulation standards}

Standards were prepared using the same protocol as the RTube experiments with the following changes: calibration standards were prepared in LC-MS water to final concentrations of $1,5,10,25,50 \mathrm{pg} / \mathrm{mL}$ and kept on ice until use. All calibration standards were infused and collected in autosampler vials using the $\mathrm{EBC}$ simulation apparatus without nebulizer gas. Three additional aliquots of the $10 \mathrm{pg} / \mathrm{mL}$ standard were prepared for the EBC simulation experiments.

\section{TURBO DECCS EBC simulation collection}

EBC simulation apparatus was the same as the RTube setup with the following changes: the $0.12 \mathrm{~mm}$ peek tubing was replaced with $0.17 \mathrm{~mm}$ stainless steel tubing to reduce back pressure on the syringe pump. Nitrogen was supplied at $60 \mathrm{psi}$ which produced a finer spray to help prevent condensation in the PET tube. Before each simulation, the syringe, tubing and nebulizer assembly was rinsed with $200 \mu \mathrm{l}$ of LC-MS methanol. The disposable DECCS sampling assembly was placed into the Turbo cooler and allowed to reach $-5{ }^{\circ} \mathrm{C}+/-0.5{ }^{\circ} \mathrm{C}$. $8-9 \mathrm{~mL}$ of low or high level standard was poured into the $10 \mathrm{~mL}$ syringe and placed into the syringe pump. The syringe was attached to the tubing and nebulizer. The gas port of the nebulizer was blocked with a blank nut. The syringe pump was set to pump $2 \mathrm{~mL}$ of standard for $7.5 \mathrm{~min}(0.3 \mathrm{~mL} /$ $\min )$. The first $2 \mathrm{~min}$ of the infusion sample were discarded. The next three $2.0 \mathrm{~mL}$ infusions were collected in a $2 \mathrm{~mL}$ autosampler vial and set aside in $4{ }^{\circ} \mathrm{C}$ fridge until ready to aliquot for analysis. Nitrogen at 60 psi was then attached to the nebulizer. The syringe pump was operated for $20 \mathrm{~s}$ to observe and verify the nebulizer spray quality. The nebulizer was then placed into the assembly and the syringe pump was programmed to run for $10 \mathrm{~min}$ (infuse $3 \mathrm{~mL}$ of condensate). At the completion of the condensate collection, the $50 \mathrm{~mL}$ collection tube was centrifuged for $2 \mathrm{~min}$ and the condensate was aliquoted into a $2 \mathrm{~mL}$ autosampler vial for analysis.

An initial experiment with the standard DECCS sampling device showed excessive adsorption of cysteinyl leukotrienes. The source of the adsorption was determined using 3 separate experimental setups $(n=3$ for each parameter). Setup \#1: DECCS assembly minus the mouthpiece with a solvent-rinsed $30 \mathrm{~mL}$ glass Corex centrifuge tube placed inside the $50 \mathrm{~mL}$ plastic collection tube; Setup \#2: Same as setup \#1 but minus the PET tube. The nebulizer was placed directly on top of the diffusing tube and the collecting tube; Setup \#3: Same as setup \#2 minus the $30 \mathrm{~mL}$ glass Corex centrifuge tube. These different parameters allowed the elimination of the PET tube and the $50 \mathrm{~mL}$ collection tube as possible sites of adsorption for the Cys-LTs.

\section{Saliva sample collection and preparation}

Each volunteer from Cohort 1 was provided with a $50 \mathrm{~mL}$ conical tube and saliva was allowed to flow naturally into the tube for 15-30 min. Approximately 3-5 mL of saliva was collected per volunteer. Samples were collected between 9:45 am and 10:30 am, approximately 2-3 $\mathrm{h}$ after eating breakfast. For Cohort 2, a "dirty" saliva sample was collected by having the subject spit into a $15 \mathrm{~mL}$ conical tube without rinsing their mouth. The subject then rinsed their mouth out 3 times with drinking water. A "clean" saliva sample was produced by having the subject chew a piece of chewing gum for 15-30 s, removing gum, and then spitting into $15 \mathrm{~mL}$ conical falcon tube; subjects were cautioned not to swish the sample in their mouth prior to spitting.

Immediately after collection, the saliva in the falcon tube was then centrifuged for $10 \mathrm{~min}$ at $3000 \mathrm{rpm}$ at $4{ }^{\circ} \mathrm{C}$ to separate the clear liquid component of the saliva from the stringy mucus portion of the sample. The supernatant was pipetted into an amber autosampler vial for untargeted LC-MS analysis. For targeted analysis, $1 \mathrm{~mL}$ of the centrifuged saliva was placed into a new falcon tube containing $50 \mu \mathrm{L}$ of internal standard $\left(\mathrm{LTB}_{4}-\mathrm{d} 4, \mathrm{LTC}_{4}-\mathrm{d} 5\right.$, $\mathrm{LTD}_{4}-\mathrm{d} 5, \mathrm{LTE}_{4}-\mathrm{d} 5$ and $\mathrm{PGE}_{2}-\mathrm{d} 4$ at $2.5 \mathrm{pg} / \mu \mathrm{L}$ in ethanol) and $4 \mathrm{~mL}$ of acetonitrile. Samples were then vortexed for $10 \mathrm{~s}$. After addition of the acetonitrile to the clarified saliva, some additional stringy mucus may appear, so the samples were then allowed to settle. Taking care not to disturb the stringy mucus, 4 separate aliquots of the sample were pipetted into $1.5 \mathrm{~mL}$ centrifuge tubes and centrifuged at $14,000 \mathrm{rpm}$ for $10 \mathrm{~min}$ at $4{ }^{\circ} \mathrm{C} .950 \mu \mathrm{L}$ of supernatant was removed and placed in a new centrifuge tube. The sample was then frozen at $-80{ }^{\circ} \mathrm{C}$ until analysis was performed. Prior to MS analysis, samples were dried in the centrifugal evaporator until $\sim 200 \mu \mathrm{L}$ of sample remained. The remaining supernatant was transferred to a $1.8 \mathrm{~mL}$ glass autosampler vial. $200 \mu \mathrm{L}$ of ethanol was added to the centrifuge tube and vortexed for $\sim 5 \mathrm{~s}$. The ethanol was transferred to the vial with the rest of the supernatant. The sample was then diluted to $1 \mathrm{ml}$ with LC-MS water and analyzed.

\section{EBC sample collection and preparation $E B C$ control experiment}

A TURBO-DECCS (Medivac, Italy) apparatus was set up to mimic a human subject breathing into an EBC collection tube (Fig. 2a) and included a saliva trap. A syringe was rinsed thoroughly with LC-MS grade water followed by LC-MS grade methanol and then attached to a syringe pump at one end. At the other end, the syringe was connected to the mouthpiece and secured with parafilm. 
The syringe pump flow rate was adjusted to allow $3 \mathrm{~mL}$ of sample to be collected in $15 \mathrm{~min}$ (average amount of EBC per person). A nitrogen dryer was attached to the side of the mouthpiece using tubing to mimic exhalation. Two blank samples were run through the device using 100\% LC-MS grade water; sample was collected for analysis and referred to as the 'blank water control'. This was followed by running spiked LC-MS grade water containing 42 amino acids $(10 \mu \mathrm{M})$ and 16 eicosanoids $(10 \mathrm{ng} / \mathrm{mL})$ as a spiked control; this sample was designated 'spiked water control'. A new TURBO-DECCS nozzle and collection tube was used for each sample. Each nozzle and tube was discarded after use.

\section{$E B C$ sample collection and preparation}

The TURBO-DECCS collection device (Medivac, Italy) was set up at room temperature and the condenser temperature was allowed to decrease until stable at $-5.5{ }^{\circ} \mathrm{C}$. This EBC collection device contains a saliva trap. A new, unused mouth piece and nozzle was supplied for each individual. Nose clips were optional. EBC was collected per ATS/ERS recommendations [30]. Subjects breathed normally into the EBC breathing apparatus for 15-20 min each. Subjects did not eat, drink, or exercise for at least two hours prior to sample collection. Approximately 2-5 mL of EBC was collected per person. For Cohort 1, samples were examined for possible salivary contamination and marked as "saliva" or "clean". Human-derived EBC samples were pooled into two groups ('clean' EBC, $12.5 \mathrm{~mL},(n=5$ subjects), and 'saliva' EBC, $8.5 \mathrm{~mL}(n=3$ subjects)) as shown in Fig. 2e, and aliquoted into $15 \mathrm{~mL}$ falcon tubes. Humanderived EBC samples and control EBC samples (blank water control and spiked water control) were immediately frozen at $-80{ }^{\circ} \mathrm{C}$ overnight, and lyophilized the following morning.

The lyophilized samples were each reconstituted in $1 \mathrm{~mL}$ of 80:20 methanol: water, briefly vortexed and centrifuged. EBC samples were then dried down in a vacuum centrifugal concentrator at $55{ }^{\circ} \mathrm{C}$ for $1.5 \mathrm{~h}$, reconstituted in $20 \mu \mathrm{L}$ of LC-MS starting buffer ( $2 \%$ of $90: 10$ acetonitrile:water with $0.1 \%$ formic acid), spun for $5 \mathrm{~s}$ to remove residue from the sides of the centrifuge tube, and transferred to an amber autosampler vial. The entire amount of each human-derived and control EBC sample was used for untargeted LC-MS analysis. For targeted analysis, immediately after collection, $400 \mu \mathrm{L}$ of internal standard $\left(\mathrm{LTB}_{4}-\mathrm{d} 4\right.$, $\mathrm{LTC}_{4}-\mathrm{d} 5, \mathrm{LTD}_{4}-\mathrm{d} 5, \mathrm{LTE}_{4}-\mathrm{d} 5$ and $\mathrm{PGE}_{2}-\mathrm{d} 4$ at $0.125 \mathrm{pg} / \mu \mathrm{L}$ in ethanol) was added to the $\mathrm{EBC}$, vortexed and then centrifuged for 10 minutes at $3000 \mathrm{rpm}$ at $4{ }^{\circ} \mathrm{C}$. The total condensate volume was measured and recorded and split evenly between 2 centrifuge tubes. LC-MS water was added to each tube to reach a final volume of $1 \mathrm{~mL}$. The samples were then frozen at $-70{ }^{\circ} \mathrm{C}$ until analysis. Note that a saliva trap was used to prevent saliva contamination in EBC samples in Cohort 3 as well as visual observation of each sample following collection. Water spiked with amino acids and eicosanoids (referred to as standards solution) was used as reference. Overall, samples were concentrated 50-fold and divided into aliquots for untargeted LC-MS, targeted LC-MS, and proteomics analysis.

\section{Untargeted metabolomics analysis Untargeted LC-MS}

Liquid chromatography was performed on an Agilent Series G2226A pump by injecting $5 \mu \mathrm{L}$ sample onto an Agilent Zorbax SB-Aq Rapid Resolution HT 2.1 x 100 mm, $1.8 \mu \mathrm{m}, 600$ bar analytical column, coupled to an Agilent Zorbax SB-Aq Narrow-Bore $2.1 \times 12.5$ mm, $5 \mu \mathrm{m}$ guard column. The autosampler tray temperature was set at $4{ }^{\circ} \mathrm{C}$ and column compartment was set at $30{ }^{\circ} \mathrm{C}$. Samples were run at a flow rate of $0.3 \mathrm{~mL} / \mathrm{min}$, using mobile phase A (water with $0.1 \%$ formic acid), and mobile phase B (90:10 acetonitrile:water with $0.1 \%$ formic acid). Gradient elution was as follows: $0-3$ min $2 \% \mathrm{~B}, 3-5 \mathrm{~min} 2-40 \% \mathrm{~B}, 5-20 \mathrm{~min}$ $40-100 \%$ B, $20-30$ min $100 \%$ B, followed by column reequilibration. An Agilent 6520 quadrupole time-of-flight mass spectrometer (Q-TOF-MS) was used to analyze samples in positive and negative ionization mode at mass range $50-1700 \mathrm{~m} / \mathrm{z}$, scan rate $2.22 \mathrm{spectra} / \mathrm{s}$, gas temperature $300^{\circ} \mathrm{C}$, and gas flow $10 \mathrm{~L} / \mathrm{min}$. The nebulizer was $30 \mathrm{psi}$, skimmer $60 \mathrm{~V}$, capillary voltage $4000 \mathrm{~V}$, and fragmentor $120 \mathrm{~V}$ in positive mode and $140 \mathrm{~V}$ in negative mode, with reference masses 121.050873 and 922.009798 for positive mode and 112.985628 and 966.000725 for negative mode (Agilent reference mix).

\section{Quality control}

To reduce false positives due to cross contamination or carryover, a new column was used. Instrument blanks (100\% methanol) were injected onto a new column and followed by 'water blanks' prior to sample analysis. Samples were run in the following order: control "blank" water, clean-EBC, saliva-EBC, spiked water control sample. Solvent blanks were run between each sample to eliminate carryover. Saliva samples were run last, followed by a series of additional blanks and laboratory instrument QCs to ensure that the instrument was operating at optimal conditions. This process greatly reduced the chances of any potential carryover from any of the samples.

\section{Data extraction and analysis}

MassHunter Profinder software (Agilent) was used to analyze the spectral data. An initial naïve feature finding algorithm was used to detect and extract peaks present in the spectrum of the samples using the following parameters: peak heights $\geq 300$ counts, ion species $+\mathrm{H},+\mathrm{Na},+\mathrm{K}$ in 
positive mode, $-\mathrm{H},+\mathrm{Br},+\mathrm{HCOO},+\mathrm{CH}_{3} \mathrm{COO}$ in negative mode, charge state maximum of 2 , ion threshold of two or more ions, alignment using $0.3 \mathrm{~min}$ retention time and $20 \mathrm{ppm}$ mass window, absolute height $\geq 1100$ counts, MFE score $\geq 90$, and a compound must be present in at least two sample files. A formula generation algorithm was used to re-mine the spectral data and reduce missing values using the following parameters: symmetric ppm of 20 , matching score $>75$, absolute peak height $\geq 1000$ counts, absolute ion filter height $\geq 1000$ counts, and a compound must be present in at least two sample files. Compounds were imported into Mass Profiler Professional (Agilent) using a minimum abundance threshold of 3000 counts. Solvent blanks and the unspiked water controls were background subtracted to eliminate any contamination from the samples during sample collection, preparation or instrument analysis; this removed 13 compounds in control water and 2 compounds in the instrument blank from the EBC samples.

\section{MS/MS analysis}

Tandem MS was performed on an Agilent 6560 IMMS Q-TOF for selected metabolites. MS/MS data was collected with a $500 \mathrm{~ms} / \mathrm{spectra}$ acquisition time. Precursor ions were isolated with a $4 \mathrm{~m} / z$ isolation width and 1 min delta retention time. Collision energies of 10, 20, and $40 \mathrm{eV}$ were applied. Fragmentation data was exported to the freely available NIST MS Search v.2.2 g GUI program [31] (NIST, Gaithersburg, MD, USA) and were matched to spectra in the NIST 14 Mass Spectral Library. This library contains 193,119 spectra representing 43,912 precursor ions and 8,351 compounds; a detailed description of the library is available [32]. Automated library searching was performed using spectrum search type 'Identity', search with "MS/MS", and default program settings. The search $m / z$ tolerance was \pm 0.4 for precursor ions and \pm 0.4 for product ions without ignoring the precursor ion. The MS search program outputted a list of matched chemical compounds including several measures of spectral similarity [33]. The Match Factor (MF) is the normalized dot product with square-root scaling of the experimental mass spectrum and a library mass spectrum, using all the elements in the experimental mass spectrum. The Reverse Match Factor (RMF) is the normalized dot product with square-root scaling of the experimental mass spectrum and the library mass spectrum, but the elements that are not present in the library mass spectrum are not included.

\section{Amino acid and eicosanoid data analysis}

The raw LC-MS .d files from the standards and samples were imported into MassHunter Quantitative Analysis Software (v.B.07.00) (Agilent Technologies, Santa Clara, $\mathrm{CA}$ ) to extract $\mathrm{m} / \mathrm{z}$ and retention times using tolerances of \pm 0.5 min for retention time window and $\pm 10 \mathrm{ppm}$ for $\mathrm{m} / \mathrm{z}$. Quantitation of amino acids and eicosanoids was based on peak areas of amino acids and eicosanoids in the samples against known spiked standards $[34,35]$.

\section{Compound identification}

Amino acids and eicosanoids in EBC and saliva were identified by matching their exact mass, isotope ratios, and retention times to purchased standards. An in-house database comprising METLIN, LIPID MAPS, Kyoto Encyclopedia of Genes and Genomes (KEGG), and human metabolome database (HMDB) was used to annotate additional detected metabolites in the untargeted data using exact mass, isotope ratio, and isotopic distribution with a mass error of $\leq 10 \mathrm{ppm}$ and a minimum database score of 70/100. Spectra were manually inspected for quality.

\section{Targeted analysis of lipid mediators by LC-MS}

Quantitation of lipid mediators was performed using 2 dimensional reverse phase HPLC tandem mass spectrometry (LC-MS/MS). The HPLC system consisted of an Agilent 1260 autosampler (Agilent Technologies, Santa Clara, CA), an Agilent 1260 binary loading pump (pump 1), an Agilent 1260 binary analytical pump (pump 2) and a 6 port switching valve. Pump 1 buffers consisted of $0.1 \%$ formic acid in water (solvent A) and 9:1 v:v acetonitrile:water with $0.1 \%$ formic acid (solvent B). Pump 2 buffers consisted of $0.01 \%$ formic acid in water (solvent $C$ ) and $1: 1$ acetonitrile:isopropanol (solvent D).

$100 \mu \mathrm{l}$ of extracted saliva or EBC was injected onto an Agilent Poroshell EC-C18 $2.1 \times 5 \mathrm{~mm} 2.7 \mu \mathrm{m}$ trapping column using pump 1 at $0.5 \mathrm{~mL} / \mathrm{min}$ for 0.5 min with a solvent composition of $95 \%$ solvent A: $5 \%$ solvent B. At $0.51 \mathrm{~min}$ the switching valve changed the flow to the trapping column from pump 1 to pump 2. The flow was reversed and the trapped lipid mediators were eluted onto an Agilent Poroshell EC-C18 2.1x150 mm $2.7 \mu \mathrm{m}$ analytical column using the following gradient at a flow rate of $0.4 \mathrm{~mL} / \mathrm{min}$ : hold at $75 \%$ solvent A:25\% solvent D from 0-0.5 min, then a linear gradient from $25-45 \% \mathrm{D}$ over $8.5 \mathrm{~min}$ followed by an increase from $45-48 \% \mathrm{D}$ from $8.5-11 \mathrm{~min}$, then from $48 \% \mathrm{D}$ to $65 \% \mathrm{D}$ over $4 \mathrm{~min}$, and then from $65-100 \% \mathrm{D}$ in $0.01 \mathrm{~min}$, finally holding at $100 \%$ D for $1 \mathrm{~min}$. During the analytical gradient pump 1 washed the injection loop with $100 \% \mathrm{~B}$ for $4 \mathrm{~min}$ at $0.5 \mathrm{~mL} / \mathrm{min}$. Both the trapping column and the analytical column were re-equilibrated at starting conditions for $4 \mathrm{~min}$ before the next injection.

Mass spectrometric analysis was performed on an Agilent 6490 triple quadrupole mass spectrometer in negative or positive ionization mode, based on compound chemistry (Additional file 1). The drying gas was $250{ }^{\circ} \mathrm{C}$ at a flow rate of $15 \mathrm{~mL} / \mathrm{min}$. The sheath gas was $350{ }^{\circ} \mathrm{C}$ at $12 \mathrm{~mL} / \mathrm{min}$. The nebulizer pressure was 35 psi. The 
capillary voltage was $3500 \mathrm{~V}$ in negative mode and $4000 \mathrm{~V}$ in positive mode.

Data for lipid mediators was acquired in dynamic MRM mode using experimentally optimized collision energies obtained by flow injection analysis of authentic standards (Additional file 1). Calibration standards for each lipid mediator were analyzed over a range of concentrations from $0.04 \mathrm{pg} / \mathrm{mL}-8 \mathrm{pg} / \mathrm{mL}$. Calibration curves for each lipid mediator were constructed using Agilent MassHunter Quantitative Analysis software. The results were calculated by obtaining the ratio of the target compound/internal standard and then using the linear equation obtained from the calibration curve $(y=m X+b)$ to get the final concentration in $\mathrm{pg} / \mathrm{mL}$.

\section{Proteomics analysis}

An aliquot of the EBC samples collected from the 13 volunteers in the replication study (Cohort 3) and grouped into 4 categories based on health status was used for proteomics analysis; $120 \mu \mathrm{L}$ healthy nonsmoker, $8 \mu \mathrm{L}$ healthy smoker, $28 \mu \mathrm{L}$ non-smoker common cold, and $6.6 \mu \mathrm{L}$ non-smoker nasal congestion. Samples were dried in a centrifugal evaporator at $45^{\circ} \mathrm{C}$. The 4 samples then underwent a trifluoroethanol (TFE) in-solution digestion overnight with trypsin. Digests were dried at $45{ }^{\circ} \mathrm{C}$ and resuspended in $10 \mu \mathrm{L}$ of $3 \%$ acetonitrile with $0.1 \%$ formic acid.

$5 \mu \mathrm{L}$ of each sample was injected onto a ProntoSil C18AQ (0.1X150mm) column from NanoLCMS Solutions. Samples were analyzed using a nanoAdvance nano flow LC (Bruker) on the front of an Impact HD Q-TOF (Bruker) with a gradient elution from $5-50 \%$ over $30 \mathrm{~min}$ at $40{ }^{\circ} \mathrm{C}$ and $800 \mathrm{~nL} / \mathrm{min}$ flow rate. Buffer A was water with $0.1 \%$ formic acid, and buffer $B$ was acetonitrile with $0.1 \%$ formic acid. Data was acquired at $2 \mathrm{~Hz}$ over a range of $150-2200 \mathrm{~m} / \mathrm{z}$. Data was processed using DataAnalysis 4.2 (Bruker), database searches were performed with Mascot v2.4 (Matrix Science), and protein assessment/ scoring was performed with ProteinScape 3.1 (Bruker).

\section{Results}

\section{Experimental set up for control experiments}

In order to test recoveries and determine background contamination, a system was developed that mimicked EBC collection. As shown in Fig. 1a, a syringe and syringe pump were attached to a nebulizer; this was used to administer sample at a controlled rate into a TURBODECCS EBC collection apparatus. An unspiked, "blank" water sample was used as a control to monitor contaminants that may be present in the collection tubing. Water spiked with amino acids and eicosanoids was used to measure recoveries; this "spiked control" was also used as a reference to verify metabolite identities in EBC using mass and retention time. As expected, no compounds were detected in the "blank" controls. In total, 30 out of the 42 spiked amino acids and 16 spiked eicosanoids were detected in the "spiked control" samples. Following method validation, $\mathrm{EBC}(n=8)$ was collected from healthy volunteers, and underwent minimal sample preparation to reduce potential for contamination. EBC was divided into clean $(n=5)$ and saliva-contaminated $(n=3)$ based on visual inspection of the samples. Note that spikes were not added to the EBC samples; this was in an effort to reduce false positives that may be present as a result of degradation of spiked standards. Figure 1b, c and d show representative total ion chromatograms (TIC) of the blank, spiked water and "clean" EBC samples respectively. Figure 1e shows EBC in tubes following collection; saliva-contaminated EBC was clearly distinguishable from non-contaminated EBC.

\section{Adsorption of compounds on EBC collection tubes: leukotriene recovery experiment}

A second control experiment (Fig. 2) was performed to determine recoveries of commonly reported EBC molecules. Because plastic tubes may result in adsorption of certain molecules, glass and plastic tubes and the addition of a coating were compared. For this experiment, known amounts of leukotrienes $(10 \mathrm{pg} / \mathrm{mL}$ and $100 \mathrm{pg} / \mathrm{mL}$ ) were injected into TURBO DECCS tubes using the apparatus in Fig. 1; RTubes were attached to the syringe pump as shown in Fig. 2. Overall, recoveries of the leukotrienes ranged between $96.9-112 \%$ depending on the collection tube used (Fig. 2c). Recoveries were higher with the glass RTube device $(58.4-98.9 \%)$ compared to the plastic RTube device $(38.6-68.5 \%)$. In experiments using the TURBO DECCS, recoveries were higher using the glass tube without PET (48.01 - 83.58\%), compared to the glass tube with PET $(20.24-87.57 \%)$, and the plastic tube without PET (49.11 - 73.78\%). These recovery experiments showed significant adsorption of cysteinyl leukotrienes to the plastic RTube by $\sim 60 \%$ compared to the glass RTube (Fig. 2c). There was also 10-22\% less adsorption of the leukotrienes to the TURBO-DECCS plastic tube compared to the plastic RTube at the $10 \mathrm{pg} / \mathrm{mL}$ spike levels (Fig. 2d). In addition, polyethylene terephthalate (PET) caused significant adsorption of $\mathrm{LTC}_{4}, \mathrm{LTD}_{4}$, and $\mathrm{LTE}_{4}$ to the coated collection tubes compared to the uncoated tubes (Fig. 2d).

\section{Comparison of eicosanoids and amino acids in healthy saliva, healthy $E B C$, and healthy saliva-EBC}

Saliva and EBC were collected from 13 healthy subjects (Cohort 1) and analyzed using LC-MS. Table 1 shows concentrations of the amino acids and eicosanoids detected in EBC and saliva of these subjects. Additional file 2 shows the extracted peak areas of selected compounds and Additional file 3 shows the separation of PGF $_{2 \alpha}$ isomers. 


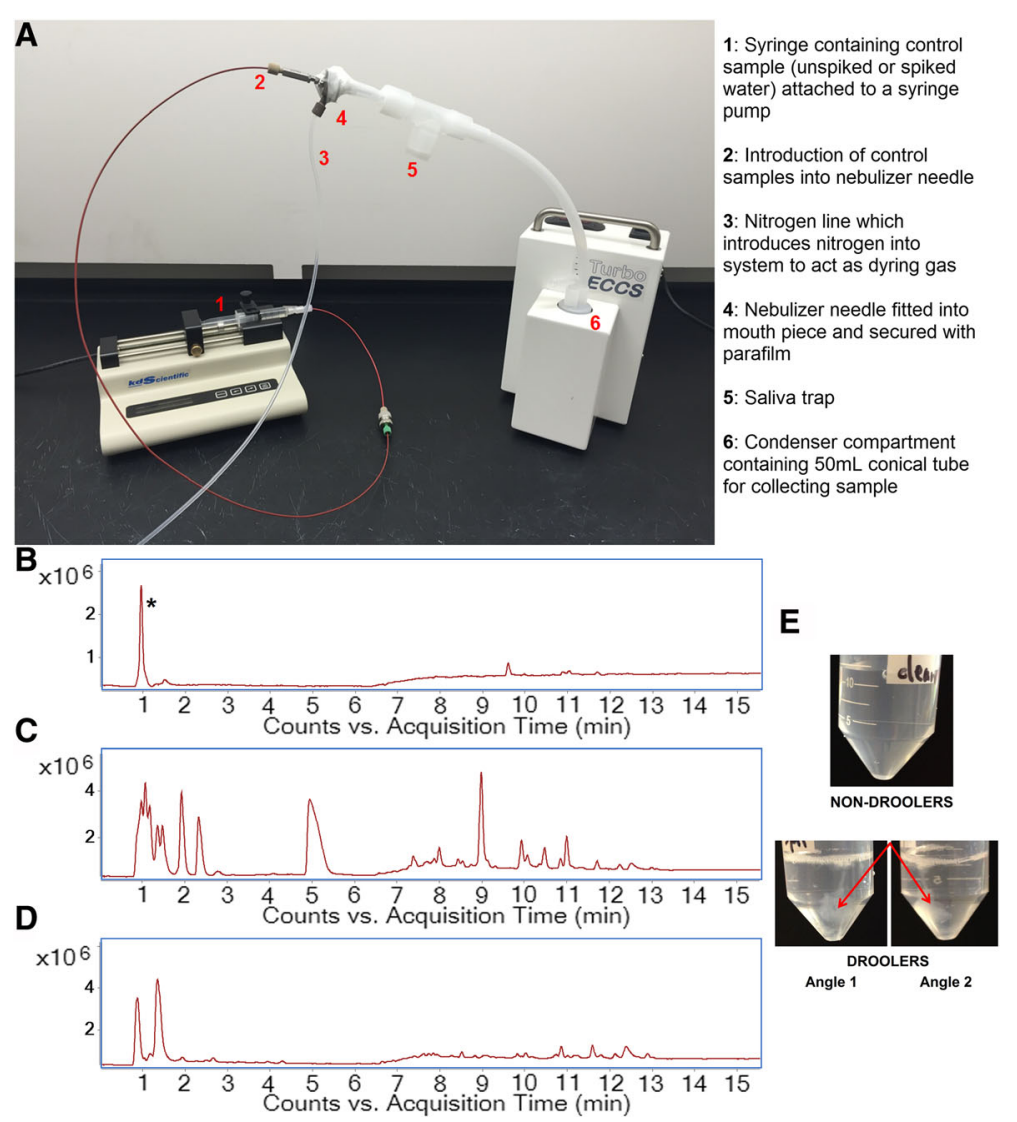

Fig. 1 Experimental setup and total ion chromatograms (TIC) of exhaled breath condensate (EBC) controls. a Setup of the control experiment using a syringe and syringe pump to administer control unspiked water and a control spiked water sample through the TURBO-DECCS EBC collection apparatus; b TIC of unspiked water. * indicates a contaminant peak at 0.933 min which was putatively identified as propiolic acid (8.69 ppm error, 82.8 score), c TIC of spiked water; $\mathbf{d}$ TIC of a 'Clean' EBC sample; e Visualization of EBC samples collected from volunteers showing the clean EBC from non-droolers, compared to EBC collected from droolers which show the presence of saliva in the samples

Three amino acids (anserine, hydroxyproline, and cysteine) were undetected in all samples including the spiked water; these molecules may be below our limit of detection or are not detectable in our system (for example due to inability to ionize). Carnosine, homocystine, lysine, methionine, and phosphoethanolamine were only detected in the spiked water; this indicates that their concentration in $E B C$ and saliva were below detection limits or that they may not be present in these biological fluids. Seven eicosanoids (protectin DX, 17(S)-HDHA, $\mathrm{LTC}_{4}, \mathrm{LTD}_{4}, \mathrm{LTE}_{4}, \mathrm{RvD1}$, and RvD2) were less than half the concentration in clean-EBC compared to saliva-EBC; they were an order of magnitude lower in concentration in clean-EBC compared to saliva. Overall, in the clean-EBC, the eicosanoids were present at concentrations ranging $10 \mathrm{pg} / \mathrm{mL}-76.5 \mathrm{ng} / \mathrm{mL}$; amino acids ranged from $196 \mathrm{pg} / \mathrm{mL}-4 \mu \mathrm{g} / \mathrm{mL}$.

Forty compounds were of higher concentration in saliva compared to clean-EBC or saliva-EBC. In addition, twenty-five compounds were present at higher concentrations in the saliva-EBC samples compared to the clean-EBC. These included the following fifteen amino acids: 1-methylhistidine/3-methylhistidine, arginine, cystathionine, ethanolamine, glutamine, L-aminoadipic acid, L-cystine, leucine/isoleucine, ornithine, phenylalanine, phosphoserine, proline, sarcosine, taurine, urea, and valine. These also include eight eicosanoids: protectin DX, 17(S)-HDHA, $\mathrm{LTC}_{4}, \mathrm{LTD}_{4}, \mathrm{LTE}_{4}, \mathrm{PGE}_{2}, \mathrm{RvD} 1$, and RvD2. These compounds are most likely elevated due to salivary contamination of the EBC samples.

Ten compounds were detected at similar concentrations in both the clean-EBC and the saliva-EBC samples. These were alanine, aspartic acid, citrulline, creatinine, $\gamma$-aminobutyric acid, glycine, hydroxylysine, LXA4, LTB 4 , and $\mathrm{PGF}_{2 \alpha}$. Four amino acids ( $\alpha$-aminobutyric acid, glutamic acid, threonine, tryptophan) and five eicosanoids $\left(11 \beta-\right.$ PGF $_{2 \alpha}, 14(\mathrm{~S})-\mathrm{HDHA}, 15 \mathrm{R}-\mathrm{PGF}_{2 \alpha}$, 8-iso-15R-PGF $2 \alpha$, 8 -iso-PGF $2 \alpha$ ) had higher concentrations in the clean-EBC compared to the saliva-EBC samples. Four compounds (asparagine, taurine, tyrosine, $\mathrm{RvD2}$ ) were undetected in $\mathrm{EBC}$ compared to saliva. Alanine was lower in concentration in saliva compared to clean-EBC and saliva-EBC while an additional six compounds (cystathionine, 11ß- 


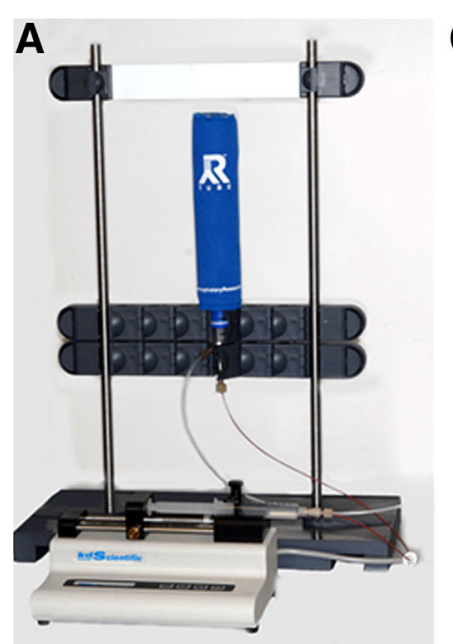

\section{C \\ R-Tube Spike Recovery Comparison Cysteinyl Leukotrienes}

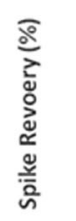

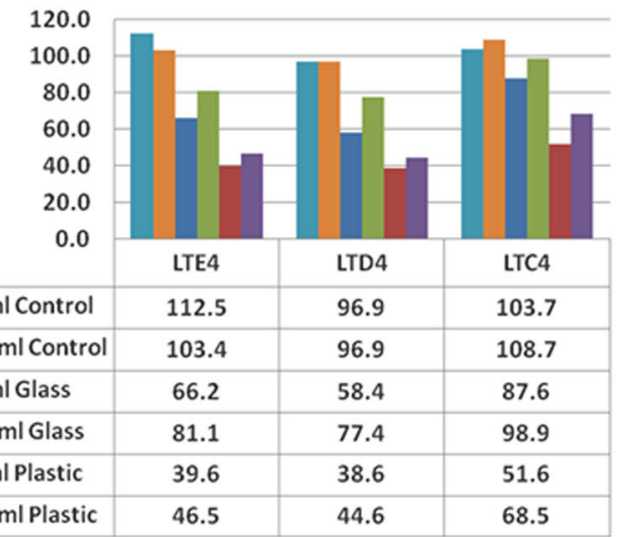

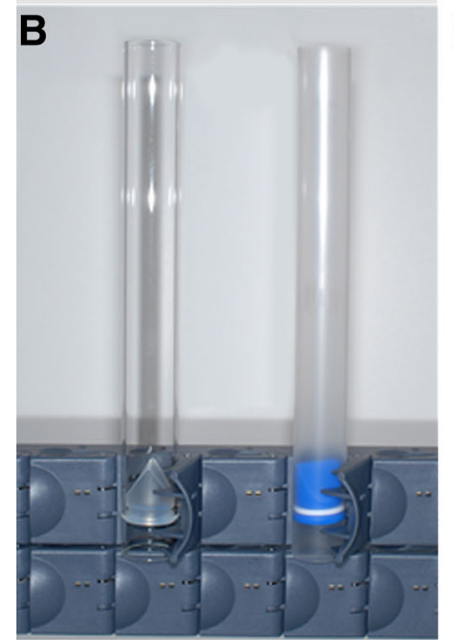

\section{Turbo DECCS Spike Recovery Comparison Leukotrienes}

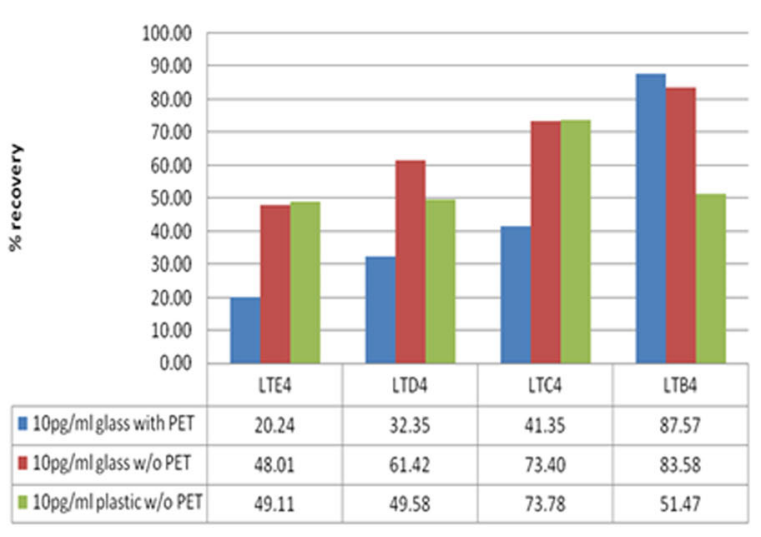

Fig. 2 Experimental setup and recoveries of leukotrienes using various exhaled breath condensate (EBC) collection devices. a EBC simulation device connected to a syringe pump, showing the plastic tube and condenser; $\mathbf{b}$ Glass (left) versus plastic (right) EBC tube; c RTube spike recovery comparison for cysteinyl leukotrienes; $\mathbf{d}$ TURBO-DECCS spike recovery comparison for leukotrienes. PET: polyethylene terephthalate

$\mathrm{PGF}_{2 \alpha}$, 15R-PGF $2 \alpha$, 8-iso-15R-PGF $2 \alpha, 8$-iso-PGF $2 \alpha$, and $\mathrm{PGE}_{2}$ ) were undetected in the saliva samples but were detected in the clean-EBC and saliva-EBC.

\section{Detection of metabolites in healthy EBC using untargeted metabolomics}

LCMS-based metabolomics was used to determine what metabolites could be detected and identified in Cohort 1 (clean EBC, saliva-EBC, and saliva) using an untargeted approach. The overlap in metabolites from the LC-MS analysis of these samples is shown in Fig. 3. Overall, there were 400 metabolites detected in all samples; 306 were present in both saliva and saliva-EBC; 77 metabolites were detected in the clean-EBC and the saliva-EBC but were undetected in the saliva samples. From the 77 metabolites detected in the EBC and saliva-EBC samples, 40 metabolites were annotated using freely available small molecule databases (Table 2); 37 were either unannotated or annotated using molecular formula (Additional file 4). Tandem MS provided additional confidence in the identification of acetylsalicylic acid, 4-chloro-L-phenylalanine, 3,4-furandicarboxylic acid, shikimic acid, succinic acid, and citric acid (Additional file 5).

\section{Analysis of eicosanoids in saliva and EBC of asthmatics}

Since EBC has potential as a clinical diagnostic in lung diseases, we sought to determine if previously reported eicosanoid molecules could be detected in clean EBC or if their detection was the result of saliva contamination. Matched saliva and EBC was collected from 107 asthmatic subjects (Cohort 2) for this purpose (Fig. 4). Eicosanoid analysis was performed using multiple reaction monitoring (MRM) on a triple quadrupole mass spectrometer (QQQ-MS). Sixteen eicosanoids comprised the panel as detailed in the methods. Only one molecule, 8iso-15R-PGF $2 \alpha$, was detected in EBC and in only one 
Table 1 Amino acid and eicosanoid concentrations in healthy human saliva and healthy EBC

\begin{tabular}{|c|c|c|c|c|c|c|}
\hline & Compound & Formula & Identifier & Clean-EBC(ng/mL) & Saliva-EBC (ng/mL) & Saliva $(\mathrm{ng} / \mathrm{mL})$ \\
\hline \multirow[t]{40}{*}{ Amino acids } & 1-methylhistidine/3-methylhistidine & $\mathrm{C} 7 \mathrm{H} 11 \mathrm{~N} 3 \mathrm{O} 2$ & $70958 / 70959$ & 518.0 & 1276.1 & 1256059 \\
\hline & a-amino-n-butyric acid/ $\beta$-aminoisobutryic acid & $\mathrm{C} 4 \mathrm{H} 9 \mathrm{NO} 2$ & 35621 & 316.3 & 41.3 & 90579 \\
\hline & Alanine/ß-Alanine & $\mathrm{C} 3 \mathrm{H} 7 \mathrm{NO} 2$ & 16449 & 58.1 & 51.9 & 13.84 \\
\hline & Anserine $^{a}$ & $\mathrm{C} 10 \mathrm{H} 16 \mathrm{~N} 4 \mathrm{O} 3$ & 18323 & ND & ND & ND \\
\hline & Arginine & $\mathrm{C} 6 \mathrm{H} 14 \mathrm{~N} 4 \mathrm{O} 2$ & 29016 & 1211.6 & 6016.8 & 101238 \\
\hline & Asparagine & $\mathrm{C} 4 \mathrm{H} 8 \mathrm{~N} 2 \mathrm{O} 3$ & 22653 & ND & 8.6 & 7575 \\
\hline & Aspartic acid & $\mathrm{C} 4 \mathrm{H} 7 \mathrm{NO} 4$ & 22660 & 10.7 & 19.4 & 11387 \\
\hline & Carnosine $^{a}$ & $\mathrm{C} 9 \mathrm{H} 14 \mathrm{~N} 4 \mathrm{O} 3$ & 15727 & ND & ND & ND \\
\hline & Citrulline & $\mathrm{C} 6 \mathrm{H} 13 \mathrm{~N} 3 \mathrm{O} 3$ & 18211 & 302.2 & 304.8 & 16922 \\
\hline & Creatinine & $\mathrm{C} 4 \mathrm{H} 7 \mathrm{~N} 3 \mathrm{O}$ & 16737 & 237.5 & 396.9 & 88368 \\
\hline & Cystathionine & $\mathrm{C} 7 \mathrm{H} 14 \mathrm{~N} 2 \mathrm{O} 4 \mathrm{~S}$ & 17755 & 930.7 & 1756.2 & ND \\
\hline & Cysteine $^{a}$ & $\mathrm{C} 3 \mathrm{H} 7 \mathrm{NO} 2 \mathrm{~S}$ & 15356 & ND & ND & ND \\
\hline & Ethanolamine & $\mathrm{C} 2 \mathrm{H} 7 \mathrm{NO}$ & 16000 & 52.5 & 230.9 & 20887 \\
\hline & $\Upsilon$-aminobutyric acid & $\mathrm{C} 4 \mathrm{H} 9 \mathrm{NO} 2$ & 16865 & 41.3 & 56.1 & 13705 \\
\hline & Glutamic acid & $\mathrm{C} 5 \mathrm{H} 9 \mathrm{NO} 4$ & 18237 & 77.0 & 29.6 & 49725 \\
\hline & Glutamine & $\mathrm{C} 5 \mathrm{H} 10 \mathrm{~N} 2 \mathrm{O} 3$ & 28300 & 24.6 & 162.4 & 18423 \\
\hline & Glycine & $\mathrm{C} 2 \mathrm{H} 5 \mathrm{NO} 2$ & 15428 & 5.99 & 11.4 & 1739 \\
\hline & Histidine & $\mathrm{C} 6 \mathrm{H} 9 \mathrm{~N} 3 \mathrm{O} 2$ & 27570 & 401.2 & 316.5 & 14751 \\
\hline & Homocystine $e^{a}$ & $\mathrm{C} 4 \mathrm{H} 9 \mathrm{NO} 2 \mathrm{~S}$ & 17485 & ND & ND & ND \\
\hline & Hydroxylysine & $\mathrm{C} 6 \mathrm{H} 14 \mathrm{~N} 2 \mathrm{O} 3$ & 60175 & 205.6 & 283.3 & 133890 \\
\hline & Hydroxyproline ${ }^{a}$ & $\mathrm{C} 5 \mathrm{H} 9 \mathrm{NO} 3$ & 24741 & ND & ND & ND \\
\hline & L-Aminoadipic acid & $\mathrm{C} 6 \mathrm{H} 11 \mathrm{NO} 4$ & 37024 & 373.3 & 696.5 & 27008 \\
\hline & L-Cystine & $\mathrm{C} 6 \mathrm{H} 12 \mathrm{~N} 2 \mathrm{O} 4 \mathrm{~S} 2$ & 17376 & 55.6 & 295.2 & 60301 \\
\hline & Leucine/Isoleucine & $\mathrm{C} 6 \mathrm{H} 13 \mathrm{NO} 2$ & $25017 / 24898$ & 100.2 & 507.1 & 99237 \\
\hline & Lysine $^{a}$ & $\mathrm{C} 6 \mathrm{H} 14 \mathrm{~N} 2 \mathrm{O} 2$ & 18019 & ND & ND & ND \\
\hline & Methionine $^{a}$ & $\mathrm{C} 5 \mathrm{H} 11 \mathrm{NO} 2 \mathrm{~S}$ & 16643 & ND & ND & ND \\
\hline & Ornithine & $\mathrm{C} 5 \mathrm{H} 12 \mathrm{~N} 2 \mathrm{O} 2$ & 18257 & 20.3 & 167.8 & 71403 \\
\hline & Phenylalanine & $\mathrm{C} 9 \mathrm{H} 11 \mathrm{NO} 2$ & 28044 & 0.196 & 78.6 & 12685 \\
\hline & Phosphoethanolamine ${ }^{a}$ & $\mathrm{C} 2 \mathrm{H} 8 \mathrm{NO} 4 \mathrm{P}$ & 36711 & ND & ND & ND \\
\hline & Phosphoserine & $\mathrm{C} 3 \mathrm{H} 8 \mathrm{NO} 6 \mathrm{P}$ & 37712 & 685.1 & 3926.3 & 329903 \\
\hline & Proline & $\mathrm{C} 5 \mathrm{H} 9 \mathrm{NO} 2$ & 26271 & 111.4 & 1088.9 & 25577 \\
\hline & Sarcosine & $\mathrm{C} 3 \mathrm{H} 7 \mathrm{NO} 2$ & 16511 & 78.0 & 143.8 & 56894 \\
\hline & Serine & $\mathrm{C} 3 \mathrm{H} 7 \mathrm{NO} 3$ & 17822 & 2.17 & 1.98 & 26140 \\
\hline & Taurine & $\mathrm{C} 2 \mathrm{H} 7 \mathrm{NO} 3 \mathrm{~S}$ & 15891 & ND & 405.7 & 53156 \\
\hline & Threonine & $\mathrm{C} 4 \mathrm{H} 9 \mathrm{NO} 3$ & 26986 & 4055.0 & 6.67 & 1223 \\
\hline & Tryptophan & $\mathrm{C} 11 \mathrm{H} 12 \mathrm{~N} 2 \mathrm{O} 2$ & 27897 & 431.3 & 245.9 & 30868 \\
\hline & Tyrosine & $\mathrm{C} 9 \mathrm{H} 11 \mathrm{NO} 3$ & 18186 & ND & 27.1 & 12607 \\
\hline & Valine & $\mathrm{C} 5 \mathrm{H} 11 \mathrm{NO} 2$ & 27266 & 57.3 & 109.8 & 25238 \\
\hline & Urea (negative mode) & $\mathrm{CH} 4 \mathrm{~N} 2 \mathrm{O}$ & 16199 & 1.56 & 51.4 & 3651 \\
\hline & Urea (positive mode) & $\mathrm{CH} 4 \mathrm{~N} 2 \mathrm{O}$ & 16199 & 2.22 & 65.1 & 5802 \\
\hline \multirow[t]{4}{*}{ Eicosanoids } & 10(S),17(S)-DiHDoHE (Protectin DX) & $\mathrm{C} 22 \mathrm{H} 32 \mathrm{O} 4$ & $871826-47-0$ & 0.084 & 0.176 & 166.83 \\
\hline & $11 \beta-P G F_{2 a}$ & $\mathrm{C} 2 \mathrm{OH} 34 \mathrm{O} 5$ & 27595 & 76.5 & 9.60 & ND \\
\hline & 14(S)-hydroxy Docosahexaenoic Acid & $\mathrm{C} 22 \mathrm{H} 32 \mathrm{O} 3$ & $119433-37-3$ & 24.9 & 6.65 & 30.76 \\
\hline & $15 R-P G F_{2 a}$ & $\mathrm{C} 2 \mathrm{OH} 34 \mathrm{O} 5$ & $37658-84-7$ & 74.8 & 9.60 & ND \\
\hline
\end{tabular}


Table 1 Amino acid and eicosanoid concentrations in healthy human saliva and healthy EBC (Continued)

\begin{tabular}{|c|c|c|c|c|c|}
\hline 17(S)-hydroxy Docosahexaenoic Acid & $\mathrm{C} 22 \mathrm{H} 32 \mathrm{O} 3$ & 155976-53-7 & 1.07 & 4.28 & 798.09 \\
\hline 8-iso-15R-PGF $2 a$ & $\mathrm{C} 2 \mathrm{OH} 34 \mathrm{O} 5$ & $214748-65-9$ & 69.0 & 9.60 & ND \\
\hline 8-iso-PGF $2 a$ & $\mathrm{C} 2 \mathrm{OH} 34 \mathrm{O} 5$ & 34505 & 72.3 & 9.60 & ND \\
\hline Lipoxin A4 (LXA4) & $\mathrm{C} 2 \mathrm{OH} 32 \mathrm{O} 5$ & 6498 & 10.4 & 14.9 & 906 \\
\hline Leukotriene $\mathrm{B}_{4}\left(\mathrm{LTB}_{4}\right)$ & $\mathrm{C} 2 \mathrm{OH} 32 \mathrm{O} 4$ & 15647 & 1.56 & 1.78 & 105 \\
\hline Leukotriene $\mathrm{C}_{4}\left(\mathrm{LTC}_{4}\right)$ & $\mathrm{C} 30 \mathrm{H} 47 \mathrm{~N} 3 \mathrm{O} 9 \mathrm{~S}$ & 16978 & 3.68 & 59.4 & 10898 \\
\hline Leukotriene $\mathrm{D}_{4}\left(\mathrm{LTD}_{4}\right)$ & $\mathrm{C} 25 \mathrm{H} 40 \mathrm{~N} 2 \mathrm{O} 6 \mathrm{~S}$ & 28666 & 0.26 & 2.85 & 175.71 \\
\hline Leukotriene $\mathrm{E}_{4}\left(\mathrm{LTE}_{4}\right)$ & C23H37NO5S & 15650 & 1.05 & 29.5 & 1842 \\
\hline Prostaglandin $\mathrm{E}_{2}\left(\mathrm{PGE}_{2}\right)$ & $\mathrm{C} 2 \mathrm{OH} 32 \mathrm{O} 5$ & 15551 & 3.87 & 31.0 & ND \\
\hline Prostaglandin $F_{2 a}\left(P_{G} F_{2 a}\right)$ & $\mathrm{C} 2 \mathrm{OH} 34 \mathrm{O} 5$ & 15553 & 0.010 & 0.010 & 2.54 \\
\hline Resolvin D1 ( $\left.R_{V} D 1\right)$ & $\mathrm{C} 22 \mathrm{H} 32 \mathrm{O} 5$ & 81564 & 3.08 & 6.91 & 2193 \\
\hline Resolvin D2 (RvD2) & $\mathrm{C} 22 \mathrm{H} 32 \mathrm{O} 5$ & 81565 & ND & 898.5 & 272983 \\
\hline
\end{tabular}

Saliva, clean-EBC, and saliva-EBC were collected from 13 healthy volunteers (Cohort 1) as described in methods. Samples were pooled and $5 \mu \mathrm{L}$ of each sample was injected onto an analytical column. Amino acids and eicosanoids were spiked into a control water sample and underwent the EBC sample collection procedure as shown in Fig. 2a. These authentic amino acid and eicosanoid standards were used to confirm compound identities in the EBC and saliva samples using exact mass, isotope ratios and retention time matching. Isomers could not be separated or differentiated using the LC-MS method described, and are listed together. ${ }^{\mathrm{ND}}$ indicates not detected. $\mathrm{ng} / \mathrm{mL}$ indicates the calculated concentration of amino acids and eicosanoids in each of the pooled samples. Compound identifiers are ChEBI except for

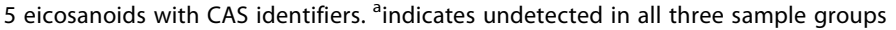

subject. Conversely, ten out of the sixteen eicosanoids were detected in a significant number of saliva samples including 8-iso-15R-PGF $2 \alpha(n=47)$, 8-iso- PGF $_{2 \alpha}(n=102)$, $\mathrm{PGF}_{2 \alpha}(n=56), \mathrm{PGE}_{2}(n=77), \mathrm{LTB}_{4}(n=105), \mathrm{LTC}_{4}$ $(n=16), \mathrm{LTD}_{4}(n=13), \mathrm{LTE}_{4}(n=13), 17(\mathrm{~S})$-HDHA $(n=79)$, and $14(\mathrm{~S})$-HDHA $(n=106)$. One eicosanoid, 14(S)-HDHA, was detected in all 106 saliva samples; this may be due to its higher concentration levels (12 pg/mL - 4014 pg/mL) compared to the other eicosanoids $(0.15 \mathrm{pg} / \mathrm{mL}-535 \mathrm{pg} / \mathrm{mL})$.

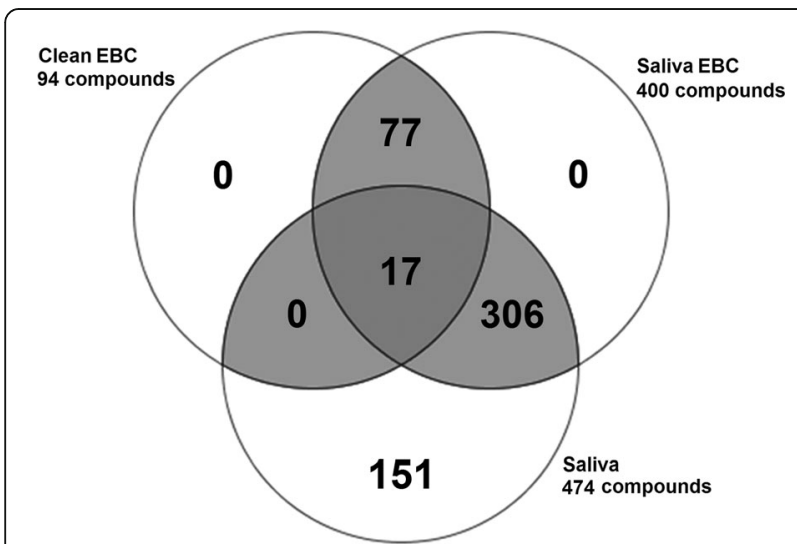

Fig. 3 Overlap of metabolites detected in clean EBC, saliva-contaminated EBC, and saliva samples of healthy volunteers in Cohort 1. Untargeted metabolomics was performed on EBC and saliva from healthy volunteers. Metabolite peaks were extracted using MassHunter Profinder software (Agilent). Samples were filtered using a 3000 abundance cutoff and a presence in at least two of the three sample groups. A total of 77 metabolites were determined to be unique to EBC
In order to determine if eicosanoids were present in $\mathrm{EBC}$ but below the limit of detection, remaining EBC from the asthmatics subjects $(n=107)$ was pooled into a single $13 \mathrm{~mL}$ aliquot and spiked with five deuterated eicosanoid standards $\left(\mathrm{PGE}_{2}-\mathrm{d} 4, \mathrm{LTB}_{4}-\mathrm{d} 4, \mathrm{LTC}_{4}-\mathrm{d} 5, \mathrm{LTD}_{4}\right.$ $\mathrm{d} 5, \mathrm{LTE}_{4}-\mathrm{d} 5$ ). The sample was lyophilized, reconstituted in $20 \mu \mathrm{L}$ of HPLC buffer, and the entire amount analyzed via LC-MS in full scan positive ionization mode. After subtracting solvent blanks, 97 metabolites were detected in EBC, including tentative identifications for $\mathrm{LTE}_{3}$, thromboxane, 11-trans-LTE 4 , 11-trans-LTC 4 , and 12-oxo- $\mathrm{LTB}_{4}$ (Additional file 6). While it is possible that these molecules were the result of degradation of the standards, this result also suggests that eicosanoids may be present in $\mathrm{EBC}$, albeit at very low concentrations.

\section{Replication experiment using targeted LC-MS, untargeted LC-MS, and proteomics to examine healthy, sick, and smoker EBC}

To confirm that small molecules are detectable in EBC and to further rule out the possibility of saliva contamination, a replication experiment was performed with EBC collected from 13 subjects (Cohort 3). Samples were classified into four groups based on health status: healthy non-smoker, healthy smoker, non-smoker with the common cold, non-smoker with nasal congestion. A saliva trap was used and subjects were observed to ensure that each participant did not contaminate the samples with saliva during the EBC collection procedure. Overall, a total of 172 metabolites were detected when untargeted LC-MS metabolomics was used (Fig. 5a); of these 118 were 
Table 2 Database annotated metabolites detected in healthy EBC

\begin{tabular}{|c|c|c|c|c|c|c|c|c|}
\hline Compound Database Annotation & Formula & Mode & $\begin{array}{l}\text { RT } \\
(\min )\end{array}$ & Mass & $\mathrm{m} / \mathrm{z}$ & Adduct & $\begin{array}{l}\text { ppm } \\
\text { error }\end{array}$ & Identifier \\
\hline \multirow[t]{2}{*}{ C25-Allenic-apo-aldehyde } & \multirow[t]{2}{*}{$\mathrm{C} 25 \mathrm{H} 34 \mathrm{O} 3$} & \multirow[t]{2}{*}{+} & \multirow[t]{2}{*}{8.24} & \multirow[t]{2}{*}{382.2508} & \multirow[t]{2}{*}{383.2579} & \multirow[t]{2}{*}[\mathrm{M}+\mathrm{H}]{+} & \multirow[t]{2}{*}{0.52} & KEGG: C14044 \\
\hline & & & & & & & & LMPR01070293 \\
\hline 19a-19-Hydroxy-3,11-dioxo-12-ursen-28-oic & $\mathrm{C} 29 \mathrm{H} 42 \mathrm{O} 5$ & + & 8.40 & 470.3055 & 471.3124 & {$[\mathrm{M}+\mathrm{H}]+$} & 3.35 & HMDB38683 \\
\hline $\begin{array}{l}\text { 2,2,4,4,-Tetramethyl-6-(1-oxopropyl)-1,3, } \\
\text { 5-cyclohexanetrione }\end{array}$ & $\mathrm{C} 13 \mathrm{H} 18 \mathrm{O} 4$ & + & 10.55 & 238.1205 & 261.1105 & {$[\mathrm{M}+\mathrm{Na}]+$} & 5.21 & HMDB33191 \\
\hline Planinin & $\mathrm{C} 21 \mathrm{H} 22 \mathrm{O} 6$ & - & 13.10 & 370.1416 & 369.1348 & {$[\mathrm{M}-\mathrm{H}]-$} & 1.88 & HMDB38236 \\
\hline \multirow[t]{2}{*}{ 25-Hydroxyvitamin D2-25-glucuronide } & \multirow[t]{2}{*}{$\mathrm{C} 34 \mathrm{H} 52 \mathrm{O} 8$} & \multirow[t]{2}{*}{+} & \multirow[t]{2}{*}{8.34} & \multirow[t]{2}{*}{588.3685} & \multirow[t]{2}{*}{606.4037} & \multirow[t]{2}{*}[\mathrm{M}+\mathrm{NH}4]{+} & \multirow[t]{2}{*}{3.81} & KEGG: C03033 \\
\hline & & & & & & & & HMDB10342 \\
\hline 3-Deoxy-3-azido-25-hydroxyvitamin D3 & $\mathrm{C} 27 \mathrm{H} 43 \mathrm{~N} 3 \mathrm{O}$ & + & 7.69 & 425.3406 & 446.2932 & {$[\mathrm{M}+\mathrm{K}-\mathrm{H} 2 \mathrm{O}]+$} & 2.64 & LMST03020677 \\
\hline 3-keto Fusidic acid & $\mathrm{C} 31 \mathrm{H} 46 \mathrm{O} 7$ & + & 8.03 & 530.3267 & 548.3616 & {$[\mathrm{M}+\mathrm{NH} 4]+$} & 5.04 & HMDB60745 \\
\hline Mumefural & $\mathrm{C} 12 \mathrm{H} 12 \mathrm{O} 9$ & - & 8.36 & 300.0481 & 299.0388 & {$[\mathrm{M}-\mathrm{H}]-$} & 6.58 & HMDB35179 \\
\hline 3-Oxooctanoic acid & $\mathrm{C} 8 \mathrm{H} 14 \mathrm{O} 3$ & + & 8.09 & 158.0940 & 159.1007 & {$[\mathrm{M}+\mathrm{H}]+$} & & HMDB10721 \\
\hline Fluometuron & $\mathrm{C} 10 \mathrm{H} 11$ F3 N2 O & - & 9.40 & 232.0823 & 463.1564 & {$[2 \mathrm{M}-\mathrm{H}]-$} & 1.49 & KEGG: C18853 \\
\hline Dibenzyl ether & $\mathrm{C} 14 \mathrm{H} 14 \mathrm{O}$ & - & 13.73 & 198.1039 & 197.0967 & {$[\mathrm{M}-\mathrm{H}]-$} & 2.85 & HMDB32078 \\
\hline Marmesin rutinoside & $\mathrm{C} 26 \mathrm{H} 34 \mathrm{O} 13$ & + & 10.16 & 554.1999 & 537.1973 & {$[\mathrm{M}+\mathrm{H}-\mathrm{H} 2 \mathrm{O}]+$} & 1.12 & HMDB41413 \\
\hline \multirow[t]{2}{*}{ Amitraz } & \multirow[t]{2}{*}{$\mathrm{C} 19 \mathrm{H} 23 \mathrm{~N} 3$} & \multirow[t]{2}{*}{+} & \multirow[t]{2}{*}{7.79} & \multirow[t]{2}{*}{293.1892} & \multirow[t]{2}{*}{316.1790} & \multirow[t]{2}{*}[\mathrm{M}+\mathrm{Na}]{+} & \multirow[t]{2}{*}{4.13} & KEGG: C10995 \\
\hline & & & & & & & & CAS: 33089-61-1 \\
\hline Glutamyl-Glycine & C10 H7 N3 O & + & 11.72 & 223.0123 & 224.0203 & {$[\mathrm{M}+\mathrm{K}-\mathrm{H} 2 \mathrm{O}]+$} & 3.63 & HMDB28819 \\
\hline de-Hypoxanthine futalosine & $\mathrm{C} 14 \mathrm{H} 16 \mathrm{O} 7$ & + & 1.77 & 296.0896 & 149.0523 & {$[\mathrm{M}+2 \mathrm{H}] 2+$} & 0.78 & KEGG: C17010 \\
\hline \multirow[t]{2}{*}{ Diethyltoluamide (DEET) } & $\mathrm{C} 12 \mathrm{H} 17 \mathrm{~N} \mathrm{O}$ & - & 16.74 & 251.1519 & 250.1451 & {$[\mathrm{M}+\mathrm{CH} 3 \mathrm{COO}]-$} & 0.05 & KEGG: C10935 \\
\hline & & & & & & & & CAS: $134-62-3$ \\
\hline 3,4-Dihydroxyfluorene & $\mathrm{C} 13 \mathrm{H} 10 \mathrm{O} 2$ & + & 11.38 & 198.0691 & 181.0661 & {$[\mathrm{M}+\mathrm{H}-\mathrm{H} 2 \mathrm{O}]+$} & 6.66 & $\begin{array}{l}\text { KEGG: C07717 } \\
\text { CAS: } 42523-20-6\end{array}$ \\
\hline $\begin{array}{l}\text { 2,3-Dihydro-2,3-dihydroxy-4-(4-methoxyphenyl)- } \\
\text { 1H-phenalen-1-one }\end{array}$ & $\mathrm{C} 20 \mathrm{H} 16 \mathrm{O} 4$ & - & 7.63 & 320.1049 & 319.0981 & {$[\mathrm{M}-\mathrm{H}]-$} & 1.49 & HMDB41463 \\
\hline $\begin{array}{l}\text { 3-Oxopregn-4-ene-20beta-carboxaldehyde } \\
\text { dioxime }\end{array}$ & $\mathrm{C} 22 \mathrm{H} 34 \mathrm{~N} 2 \mathrm{O} 2$ & + & 8.66 & 358.2620 & 422.2817 & $\begin{array}{l}{[\mathrm{M}+\mathrm{ACN}+} \\
\mathrm{Na}]+\end{array}$ & 9.24 & KEGG: C15106 \\
\hline $\begin{array}{l}\text { Hyperin 2"-[glucosyl-(1-> 3)-rhamnoside] } \\
\text { 6"-rhamnoside }\end{array}$ & $\mathrm{C} 39 \mathrm{H} 50 \mathrm{O} 25$ & - & 12.42 & 918.2638 & 917.2567 & {$[\mathrm{M}-\mathrm{H}]-$} & 0.20 & HMDB39911 \\
\hline Mangostanol & $\mathrm{C} 24 \mathrm{H} 26 \mathrm{O} 7$ & - & 13.02 & 426.1679 & 485.1805 & {$[\mathrm{M}+\mathrm{CH} 3 \mathrm{COO}]-$} & 3.73 & HMDB29868 \\
\hline Oleoside dimethyl ester & $\mathrm{C} 18 \mathrm{H} 26 \mathrm{O} 11$ & - & 9.79 & 418.1475 & 453.1160 & {$[\mathrm{M}+\mathrm{Cl}]-$} & 1.23 & HMDB31350 \\
\hline N-Acetyl-6-O-L-fucosyl-D-glucosamine & $\mathrm{C} 14 \mathrm{H} 25 \mathrm{~N} \mathrm{O} 10$ & - & 8.49 & 349.1370 & 348.1292 & {$[\mathrm{M}-\mathrm{H} 2 \mathrm{O}-\mathrm{H}]-$} & 3.03 & HMDB02220 \\
\hline & & & & & & & & $\begin{array}{l}\text { CAS: } 109582-58- \\
3\end{array}$ \\
\hline Oleanolic acid 3-O-beta-D-glucosiduronic acid & $\mathrm{C} 36 \mathrm{H} 56$ O9 & + & 8.40 & 632.3924 & 650.4312 & {$[\mathrm{M}+\mathrm{NH} 4]+$} & 6.2 & KEGG: C08964 \\
\hline Methionyl-Arginine & $\mathrm{C} 11 \mathrm{H} 23 \mathrm{~N} 5 \mathrm{O} 3 \mathrm{~S}$ & + & 11.97 & 305.1522 & 288.1497 & {$[\mathrm{M}+\mathrm{H}-\mathrm{H} 2 \mathrm{O}]+$} & 2.01 & HMDB28967 \\
\hline N-Cyclopropylammelide & $\mathrm{C} 6 \mathrm{H} 8 \mathrm{~N} 4 \mathrm{O} 2$ & - & 9.27 & 204.0403 & 203.0329 & {$[\mathrm{M}-\mathrm{Cl}]-$} & 8.76 & KEGG: C14149 \\
\hline PE(34:1)-15-isoLG hydroxylactam & $\mathrm{C} 59 \mathrm{H} 104 \mathrm{~N} \mathrm{O} 13$ & + & 10.01 & 1065.7160 & 1088.7032 & {$[\mathrm{M}+\mathrm{Na}]+$} & 7.06 & KEGG: C06254 \\
\hline & & & & & & & & LMGP00000061 \\
\hline $\operatorname{PE}(44: 7)$ & C49 H84 N O8 P & + & 9.75 & 845.5867 & 868.5782 & {$[\mathrm{M}+\mathrm{Na}]+$} & 5.18 & KEGG: C00350 \\
\hline & & & & & & & & HMDB09700 \\
\hline Prostaglandin $\mathrm{F}_{2 \mathrm{a}}$-biotin & C35 H60 N4 O6 S & + & 8.71 & 664.4234 & 669.3982 & {$[\mathrm{M}+\mathrm{Na}-\mathrm{H} 2 \mathrm{O}]+$} & 7.77 & \\
\hline Prostaglandin D2-biotin & $\mathrm{C} 36 \mathrm{H} 60 \mathrm{~N} 4 \mathrm{O} 6 \mathrm{~S}$ & + & 8.47 & 676.4234 & 694.4563 & {$[\mathrm{M}+\mathrm{NH} 4]+$} & 1.30 & \\
\hline Prostaglandin E2-biotin & C35 H58 N4 O6 S & + & 8.24 & 662.4045 & 663.4127 & {$[\mathrm{M}+\mathrm{NH} 4]+$} & 1.63 & \\
\hline Tyrosol-histidine & $\mathrm{C} 15 \mathrm{H} 18 \mathrm{~N} 4 \mathrm{O} 4$ & + & 7.90 & 300.1224 & 301.1300 & {$[\mathrm{M}+\mathrm{H}-\mathrm{H} 2 \mathrm{O}]+$} & 2.79 & HMDB29107 \\
\hline
\end{tabular}


Table 2 Database annotated metabolites detected in healthy EBC (Continued)

\begin{tabular}{|c|c|c|c|c|c|c|c|c|}
\hline S-Farnesyl Thioacetic Acid & $\mathrm{C} 17 \mathrm{H} 28 \mathrm{O} 2 \mathrm{~S}$ & + & 7.44 & 296.1797 & 297.1891 & {$[\mathrm{M}+\mathrm{H}]+$} & 0.87 & CAS: $135784-48-4$ \\
\hline \multirow[t]{2}{*}{ Terbucarb } & \multirow[t]{2}{*}{$\mathrm{C} 17 \mathrm{H} 27 \mathrm{~N} \mathrm{O} 2$} & \multirow[t]{2}{*}{+} & \multirow[t]{2}{*}{13.58} & \multirow[t]{2}{*}{277.2047} & \multirow[t]{2}{*}{278.2088} & \multirow[t]{2}{*}[\mathrm{M}+\mathrm{H}]{+} & \multirow[t]{2}{*}{9.9} & KEGG: C19129 \\
\hline & & & & & & & & CAS: 1918-11-2 \\
\hline \multirow[t]{3}{*}{ 8-Hydroxypinoresinol 4-glucoside } & \multirow[t]{3}{*}{$\mathrm{C} 26 \mathrm{H} 32 \mathrm{O} 12$} & \multirow[t]{3}{*}{+} & \multirow[t]{3}{*}{9.95} & \multirow[t]{3}{*}{536.1894} & \multirow[t]{3}{*}{537.1986} & \multirow[t]{3}{*}[\mathrm{M}+\mathrm{H}]{+} & \multirow[t]{3}{*}{6.55} & KEGG: C07149 \\
\hline & & & & & & & & HMDB14643 \\
\hline & & & & & & & & CAS: $26171-23-3$ \\
\hline \multirow[t]{2}{*}{ Ganglioside $\mathrm{GM}_{3}$ (d18:0/20:0) } & \multirow[t]{2}{*}{ C61 H114 N2 O21 } & \multirow[t]{2}{*}{+} & \multirow[t]{2}{*}{10.09} & \multirow[t]{2}{*}{1210.7914} & \multirow[t]{2}{*}{597.3970} & \multirow{2}{*}{$\begin{array}{l}(\mathrm{M}+2 \mathrm{H})+ \\
2[-\mathrm{H} 2 \mathrm{O}]+\end{array}$} & & KEGG: C04730 \\
\hline & & & & & & & & HMDB11919 \\
\hline Beta-Santalic acid & $\mathrm{C} 15 \mathrm{H} 22 \mathrm{O} 2$ & - & 15.63 & 234.1620 & 233.1548 & {$[\mathrm{M}-\mathrm{H}]-$} & 2.93 & HMDB39621 \\
\hline Phenylalanyl-Histidine & $\mathrm{C} 15 \mathrm{H} 18 \mathrm{~N} 4 \mathrm{O} 3$ & + & 7.77 & 302.1379 & 285.1354 & {$[\mathrm{M}+\mathrm{H}-\mathrm{H} 2 \mathrm{O}]+$} & 2.81 & HMDB28997 \\
\hline \multirow[t]{2}{*}{ 4-Hydroxyphenylacetaldehyde } & \multirow[t]{2}{*}{$\mathrm{C} 8 \mathrm{H} 8 \mathrm{O} 2$} & \multirow[t]{2}{*}{-} & \multirow[t]{2}{*}{9.28} & \multirow[t]{2}{*}{136.0524} & \multirow[t]{2}{*}{135.0450} & \multirow[t]{2}{*}[\mathrm{M}-\mathrm{H}]{-} & \multirow[t]{2}{*}{3.11} & KEGG: C03765 \\
\hline & & & & & & & & HMDB03767 \\
\hline Pimelylcarnitine & C14 H25 N O6 & - & 8.98 & 303.1682 & 284.1487 & {$[\mathrm{M}-\mathrm{H} 2 \mathrm{O}-\mathrm{H}]-$} & 3.87 & CAS: 7339-87-9 \\
\hline
\end{tabular}

database annotated and 81 metabolites were common to all four groups. While the sample numbers are too low to enable the use of statistics, it is useful to discuss the results in the context of the individual groups. The healthy group contained the least number of metabolites (112) compared to the smoker (141), common cold (150), and nasal congestion (164) groups (Fig. 5a, b). Amino acids and their derivatives were unique to the smoker EBC (Table 3). A complete list of annotated and MS/MS hits is available in Additional file 7.

Targeted analysis of 32 eicosanoids resulted in the detection of 19 compounds in the smoker group; these were undetected or below our limit of quantitation in the other three EBC groups (Additional file 8). Seven of those eicosanoids were part of the cyclooxygenase pathway, 9 were part of the 5-, 12-, or 15-lipoxygenase pathways, and 2 were in the lipid peroxidation/oxidative stress pathway. Four eicosanoids were detected and quantified in all four groups (Fig. 5c). The smoker and the nasal congestion group showed elevated levels of 13-HODE, 13-OxoODE, 9-HODE, and 9-OxoODE compared to the healthy and common cold groups. A comprehensive pathway analysis was performed across all sample groups (Additional File 9) which showed that more pathways were detected in the smoker EBC compared to the other groups in that cohort. Pathway analysis also included Cohorts 1 and 2, of which the saliva-based samples showed a greater number of pathways compared to the EBC-only samples. These results were not unexpected as the saliva samples contained a larger number of compounds than the EBC samples.

Three proteins were detected in EBC samples of Cohort 3 subjects following proteomics analysis (Table 4). Zinc finger protein 800 and myoneurin were only detected in the smoker EBC. Cytokeratin 9 was only detected in the healthy EBC. No proteins were detected in the nasal congestion or common cold EBC.

\section{Discussion}

The purpose of this study was to determine the utility of EBC in studying lung diseases, especially asthma. Therefore, we aimed to (1) evaluate whether compound adsorption to collection tubes is the reason for low-tono detection of metabolites in some EBC studies, (2) characterize the constituents of EBC using untargeted and targeted mass spectrometry, and (3) determine if the detection of molecules in EBC is due to saliva contamination during sample collection. Initial EBC experiments using the RTube for sample collection yielded no detectable levels of leukotrienes in our previous studies (data not shown). Other studies have also showed the RTube to be less sensitive than other commercially available EBC collection devices [36]. Since there is the possibility of binding of compounds to the sides of the collection tube, a control experiment was performed (Fig. 1). Results showed $10-22 \%$ less adsorption of the leukotrienes to the TURBO-DECCS plastic tube compared to the plastic RTube at the $10 \mathrm{pg} / \mathrm{mL}$ spike levels (Fig. 1d). In addition, polyethylene terephthalate (PET) caused significant adsorption of $\mathrm{LTC}_{4}, \mathrm{LTD}_{4}$, and $\mathrm{LTE}_{4}$ to the coated collection tubes (Fig. 1d). Therefore, our clinical experiments used the TURBO-DECCS plastic collection tube without PET to minimize adsorption of compounds to the plastic.

Our first goal was to identify the contribution of saliva to EBC measurements by determining concentrations of amino acids and eicosanoids in both EBC and saliva. We observed that the concentration of several eicosanoids and amino acids (Table 1) were orders of magnitude higher in saliva compared to clean-EBC and saliva-EBC. 


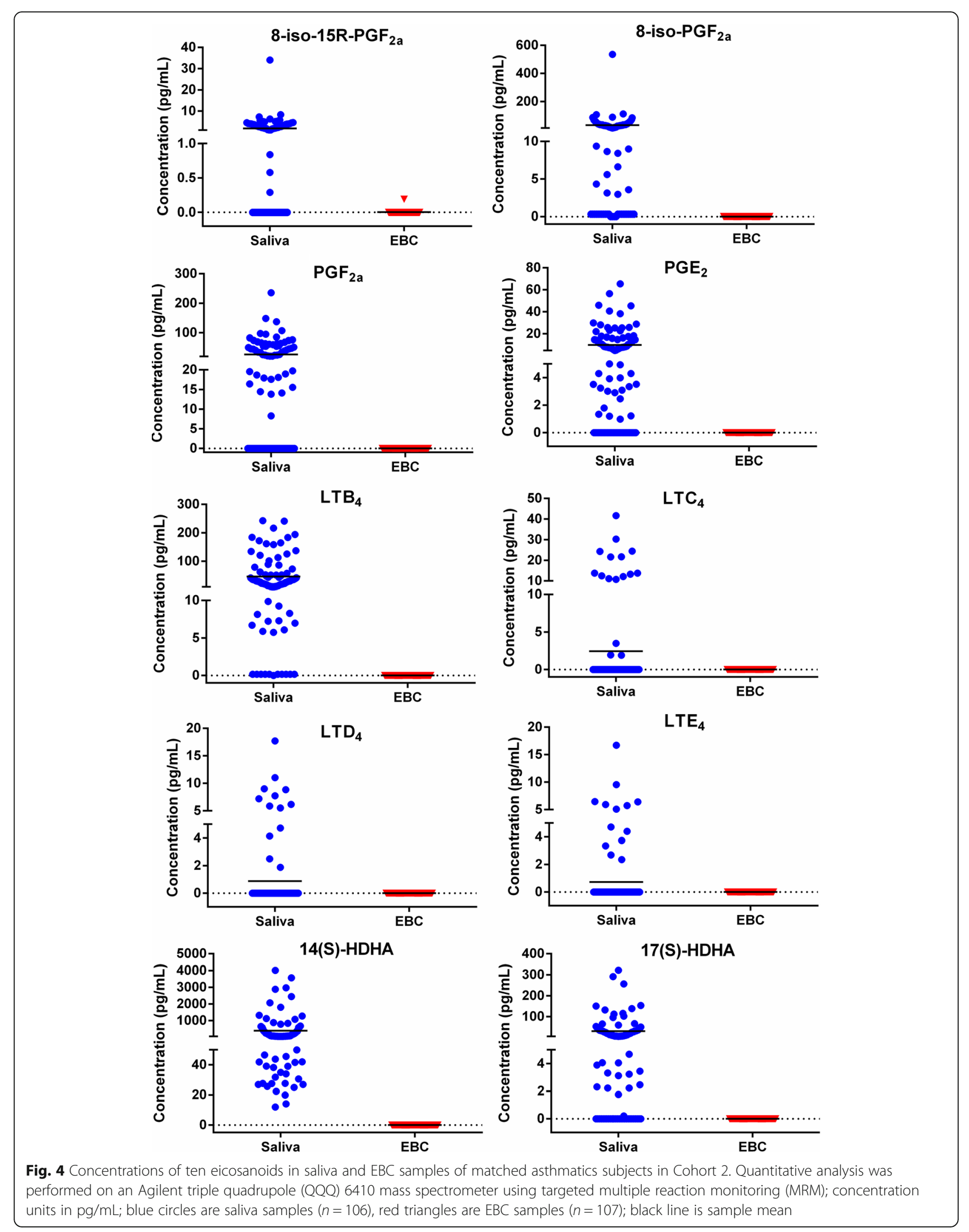




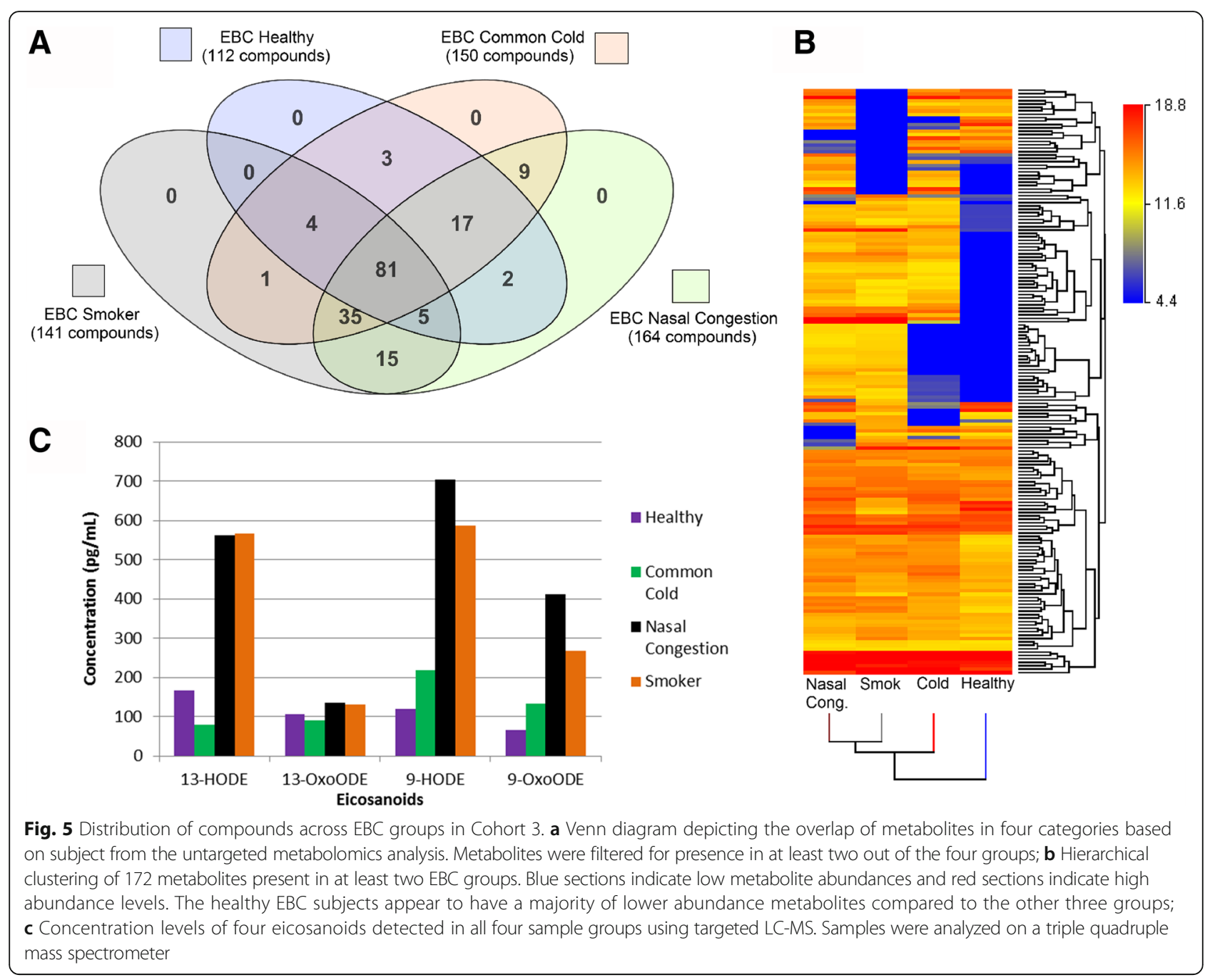

Although a saliva trap was used, it may be possible that saliva contributed to the $\mathrm{ng} / \mathrm{mL}$ concentration values obtained in both the clean-EBC and saliva-EBC sample group. As suggested by Gaber et al [25], even the slightest amount of saliva can generate false positives in EBC samples when sensitive detection methods are used. Since $\mathrm{LTB}_{4}$ is present in the nasal mucosa, and the oropharyngeal tract contributes to the contents of $\mathrm{EBC}$, a more sensitive or alternate method to alpha-amylase detection may be required to confirm saliva contamination. In our study, we detected small molecules in EBC and saliva-EBC which were not detected in the saliva-only samples. This suggests that these molecules may be specific to EBC or have much lower concentrations in saliva; therefore, the low saliva content would not contribute to their detection in EBC. These EBC constituents may potentially be used as biomarkers; however, further study is required to confirm their identities and usefulness in studying lung disease.
Previous investigations have reported the presence of eicosanoids in EBC [11, 15, 37, 38]. Many of these groups have reported higher concentrations of eicosanoids than those shown in Table 1 of the current study; the majority of these studies were conducted in the context of lung disease such as asthma where elevated levels may due to inflammation. The healthy volunteers in our study had no history of asthma or lung inflammation; this could explain the lower levels which we report. We compared our concentration values of amino acids and eicosanoids in Table 1 to those available in the literature for EBC and saliva. $\mathrm{LTB}_{4}$ has been reported to have an average concentration in saliva of $0.467 \mathrm{ng} / \mathrm{mL}$ [25] which is similar to our estimated value of $1.56 \mathrm{ng} / \mathrm{mL}$. Tyrosine has been reported at an average of $33.3 \mathrm{ng} / \mathrm{mL}$ [24] in EBC while Conventz et al [19] reported an average value of $15.5 \mathrm{ng} / \mathrm{mL}$. We detected tyrosine at $27.1 \mathrm{ng} / \mathrm{mL}$ in 'saliva-EBC' but it was undetected in 'clean-EBC'. Our proline estimate was $111.4 \mathrm{ng} / \mathrm{mL}$ in EBC. This was twice 
Table 3 Compounds detected in healthy, sick, and smoker EBC

\begin{tabular}{|c|c|c|c|c|c|c|c|c|c|}
\hline Compound & Smoker & Nasal & Cold & Healthy & RT (mins) & Mass & Formula & Mode & Identifier \\
\hline 1,3-Dicyclohexylurea ${ }^{a}$ & $\checkmark$ & $\checkmark$ & $\checkmark$ & $\checkmark$ & 8.876 & 224.1889 & $\mathrm{C} 13 \mathrm{H} 24 \mathrm{~N} 2 \mathrm{O}$ & + & CAS: $2387-23-7$ \\
\hline 13,14-dihydro Prostaglandin F1a & $\checkmark$ & $\checkmark$ & $\checkmark$ & $\checkmark$ & 6.814 & 358.2736 & $\mathrm{C} 20 \mathrm{H} 38 \mathrm{O} 5$ & + & CAS: $20592-20-5$ \\
\hline 1-Hydroxy-2-naphthoic acid & $\checkmark$ & $\checkmark$ & $\checkmark$ & $\checkmark$ & 6.258 & 188.0472 & $\mathrm{C} 11 \mathrm{H} 8 \mathrm{O} 3$ & + & KEGG: C03203 \\
\hline 2-Amino-3,7-dideoxy-D-threo-hept-6-ulosonic acid & $\checkmark$ & $\checkmark$ & $\checkmark$ & $\checkmark$ & 6.380 & 213.0620 & $\mathrm{C} 7 \mathrm{H} 13 \mathrm{~N} \mathrm{O} 5$ & + & KEGG: C16850 \\
\hline C14 sphingosine & $\checkmark$ & $\checkmark$ & $\checkmark$ & $\checkmark$ & 9.628 & 271.2141 & $\mathrm{C} 14 \mathrm{H} 29 \mathrm{~N} \mathrm{O} 2$ & - & LMSP01040006 \\
\hline N-Acetyl-D-fucosamine & $\checkmark$ & $\checkmark$ & $\checkmark$ & $\checkmark$ & 8.079 & 205.0950 & $\mathrm{C} 8 \mathrm{H} 15 \mathrm{~N} \mathrm{O} 5$ & + & KEGG: C15480 \\
\hline p-Cymene & $\checkmark$ & $\checkmark$ & $\checkmark$ & $\checkmark$ & 9.382 & 152.1205 & $\mathrm{C} 10 \mathrm{H} 14$ & + & KEGG: C06575 \\
\hline Ureidoglycine & $\checkmark$ & $\checkmark$ & $\checkmark$ & $\checkmark$ & 0.980 & 380.0903 & $\mathrm{C} 3 \mathrm{H} 7 \mathrm{~N} 3 \mathrm{O} 3$ & - & KEGG: C02091 \\
\hline 15(S)-HPETE & $\checkmark$ & $\checkmark$ & & $\checkmark$ & 10.185 & 264.2089 & $\mathrm{C} 20 \mathrm{H} 32 \mathrm{O} 4$ & + & KEGG: C05966 \\
\hline 6-hydroxy caproic acid & $\checkmark$ & $\checkmark$ & $\checkmark$ & & 6.131 & 174.0890 & $\mathrm{C} 6 \mathrm{H}_{12} \mathrm{O} 3$ & - & KEGG: C06103 \\
\hline Homoserine & $\checkmark$ & $\checkmark$ & $\checkmark$ & & 6.707 & 215.0406 & $\mathrm{C} 4 \mathrm{H} 9 \mathrm{~N} \mathrm{O} 3$ & - & KEGG: C00263 \\
\hline $\mathrm{PA}(22: 2 / 0: 0)$ & $\checkmark$ & $\checkmark$ & $\checkmark$ & & 6.118 & 490.3105 & C25 H47 O7 P & - & KEGG: C00416 \\
\hline $\operatorname{PI}(12: 0 / 12: 0)$ & $\checkmark$ & $\checkmark$ & $\checkmark$ & & 5.703 & 698.3983 & C33 H63 O13 P & - & KEGG: C01194 \\
\hline Tetrahydrodipicolinate & $\checkmark$ & $\checkmark$ & $\checkmark$ & & 7.780 & 153.0427 & $\mathrm{C} 7 \mathrm{H} 9 \mathrm{~N} \mathrm{O} 4$ & - & KEGG: C03972 \\
\hline Threonine & $\checkmark$ & $\checkmark$ & $\checkmark$ & & 8.939 & 233.0513 & $\mathrm{C} 4 \mathrm{H} 9 \mathrm{~N} \mathrm{O} 3$ & - & KEGG: C00188 \\
\hline 2-Oxo-4-hydroxy-5-aminovalerate & $\checkmark$ & $\checkmark$ & & & 1.604 & 129.0426 & $\mathrm{C} 5 \mathrm{H} 9 \mathrm{~N} \mathrm{O} 4$ & - & KEGG: C05941 \\
\hline N-Acetyl leucine & $\checkmark$ & $\checkmark$ & & & 5.710 & 173.1055 & $\mathrm{C} 8 \mathrm{H} 15 \mathrm{~N} \mathrm{O} 3$ & - & KEGG: C02710 \\
\hline 2-Amino-m-cresol ${ }^{a}$ & $\checkmark$ & & & & 0.811 & 123.0684 & $\mathrm{C} 7 \mathrm{H} 9 \mathrm{NO}$ & + & CAS: 2835-97-4 \\
\hline 3-Cyano-6-methoxycoumarin ${ }^{a}$ & $\checkmark$ & & & & 5.936 & 201.0426 & $\mathrm{C} 11 \mathrm{H} 7 \mathrm{~N} \mathrm{O} 3$ & + & - \\
\hline 3-Methylhistidine ${ }^{a}$ & $\checkmark$ & & & & 0.809 & 169.0851 & $\mathrm{C} 7 \mathrm{H} 11 \mathrm{~N} 3 \mathrm{O} 2$ & + & KEGG: C01152 \\
\hline 4-Imidazoleacrylic acid ${ }^{a}$ & $\checkmark$ & & & & 5.023 & 138.0429 & $\mathrm{C} 6 \mathrm{H} 6 \mathrm{~N} 2 \mathrm{O} 2$ & + & HMDB00301 \\
\hline 5-Aminosalicylic acid ${ }^{a}$ & $\checkmark$ & & & & 1.612 & 153.0426 & $\mathrm{C} 7 \mathrm{H} 7 \mathrm{~N} \mathrm{O} 3$ & + & KEGG: C07138 \\
\hline Acetyl arginine $e^{a}$ & $\checkmark$ & & & & 4.910 & 216.1222 & $\mathrm{C} 8 \mathrm{H} 16 \mathrm{~N} 4 \mathrm{O} 3$ & + & HMDB04620 \\
\hline Arginine $^{a}$ & $\checkmark$ & & & & 0.810 & 174.1117 & $\mathrm{C} 6 \mathrm{H} 14 \mathrm{~N} 4 \mathrm{O} 2$ & + & KEGG: C02385 \\
\hline Carnosine $^{a}$ & $\checkmark$ & & & & 0.809 & 226.1066 & $\mathrm{C} 9 \mathrm{H} 14 \mathrm{~N} 4 \mathrm{O} 3$ & + & KEGG: C00386 \\
\hline D-erythro-Sphinganine ${ }^{a}$ & $\checkmark$ & & & & 5.186 & 301.2981 & $\mathrm{C} 18 \mathrm{H} 39 \mathrm{~N} \mathrm{O} 2$ & + & LMSP01020001 \\
\hline Triethyl citrate ${ }^{a}$ & $\checkmark$ & & & & 7.519 & 276.1209 & $\mathrm{C} 12 \mathrm{H} 20 \mathrm{O} 7$ & + & CAS: 77-93-0 \\
\hline Tryptophan $^{a}$ & $\checkmark$ & & & & 4.079 & 204.0899 & $\mathrm{C} 11 \mathrm{H} 12 \mathrm{~N} 2 \mathrm{O} 2$ & + & KEGG: C00078 \\
\hline 1alpha,24,25,28-tetrahydroxyvitamin D2 & & $\checkmark$ & $\checkmark$ & & 6.213 & 460.3189 & $\mathrm{C} 28 \mathrm{H} 44 \mathrm{O} 5$ & - & LMST03010055 \\
\hline MG(18:1) & & $\checkmark$ & $\checkmark$ & $\checkmark$ & 8.908 & 373.3185 & $\mathrm{C} 21 \mathrm{H} 40 \mathrm{O} 4$ & + & KEGG: C01885 \\
\hline$P C(18: 1 / 22: 6)$ & & $\checkmark$ & $\checkmark$ & $\checkmark$ & 6.813 & 831.5785 & $\mathrm{C} 48 \mathrm{H} 82 \mathrm{~N} \mathrm{O} 8 \mathrm{P}$ & + & KEGG: C00157 \\
\hline$P G(18: 4 / 20: 4)$ & & $\checkmark$ & $\checkmark$ & $\checkmark$ & 12.183 & 790.4734 & C44 H71 O10 P & + & KEGG: C00344 \\
\hline O-decanoyl-R-carnitine & & $\checkmark$ & $\checkmark$ & & 6.305 & 361.2453 & $\mathrm{C} 17 \mathrm{H} 33 \mathrm{~N} \mathrm{O} 4$ & - & KEGG: C03299 \\
\hline Palmitoylglycine & & $\checkmark$ & & $\checkmark$ & 9.931 & 335.2469 & $\mathrm{C} 18 \mathrm{H} 35 \mathrm{~N} \mathrm{O} 3$ & + & HMDB13034 \\
\hline Arogenate & & & $\checkmark$ & $\checkmark$ & 6.828 & 227.0775 & $\mathrm{C} 10 \mathrm{H} 13 \mathrm{~N} \mathrm{O} 5$ & - & KEGG: C00826 \\
\hline a-Lipoic acid ${ }^{a}$ & & & $\checkmark$ & & 5.666 & 206.0435 & $\mathrm{C} 8 \mathrm{H} 14 \mathrm{O}_{2} \mathrm{~S} 2$ & + & KEGG: C00725 \\
\hline Ephedrine $^{a}$ & & & $\checkmark$ & & 31.317 & 165.1154 & $\mathrm{C} 10 \mathrm{H} 15 \mathrm{NO}$ & + & KEGG: C01575 \\
\hline 3-Acetyl-8-methoxycoumarin ${ }^{a}$ & & & $\checkmark$ & & 5.846 & 218.0579 & $\mathrm{C} 12 \mathrm{H} 10 \mathrm{O} 4$ & + & HMDB34345 \\
\hline 6-Hydroxymelatonin ${ }^{a}$ & & & & $\checkmark$ & 1.184 & 248.1161 & $\mathrm{C} 13 \mathrm{H} 16 \mathrm{~N} 2 \mathrm{O} 3$ & + & KEGG: C05643 \\
\hline
\end{tabular}

EBC was collected from 13 volunteers and pooled into four groups; healthy smokers, healthy non-smokers, non-smokers with nasal congestion, and non-smokers with the common cold. $\checkmark$ indicates that a compound was detected. ${ }^{a}$ indicates tandem MS fragmentation patterns were matched to the NIST14 Mass Spectral library using the NIST MS Search v.2.2 g program. MF: match factor; RMF: reverse match score. The fragmentation spectra for the listed compounds are available in the Additional file 7 
Table 4 Proteins detected in healthy non-smoker and healthy smoker EBC

\begin{tabular}{|c|c|c|c|c|}
\hline Protein & Accession ID & Smoker & Nasal Congestion & Healthy \\
\hline Zinc finger protein 800 & UniProtKB Q2TB10 & $\checkmark$ & & \\
\hline Myoneurin & UniProtKB Q9NPC7 & $\checkmark$ & & \\
\hline Keratin, type 1 cytoskeleton 9 (Cytokeratin 9) & UniProtKB P35527 & & & $\checkmark$ \\
\hline
\end{tabular}

as high as the previously reported high value in healthy subjects of $51.9 \mathrm{ng} / \mathrm{mL}$ [19] and may be the result of individual subject differences, sample preparation, or detection method. Reported EBC urea values have similar ranges within the same order of magnitude to our calculated values. Effros et al [39] reported values in the range 0.33 to $0.39 \mu \mathrm{mol} / \mathrm{L}$ (19.8 to $23.4 \mathrm{ng} / \mathrm{mL}$ ). Folesani et al [40] reported EBC urea concentrations found in healthy controls in the range $0.7-1.3 \mu \mathrm{M}(42.0$ to $78.1 \mathrm{ng} / \mathrm{mL})$. Dwyer et al [41] reported EBC urea averaged 0.52 +/$0.12 \mu \mathrm{mol} / \mathrm{L}(31.2 \mathrm{ng} / \mathrm{mL})$ in 18 individuals. Our detected levels ranged from $1.56 \mathrm{ng} / \mathrm{mL}$ (clean-EBC) to $65.1 \mathrm{ng} / \mathrm{mL}$ (saliva-EBC) which falls within the same order of magnitude of these previously reported values. The differences among studies could be accounted for by variations in sample preparation procedures such as lyophilization, as well as differences in methods of collecting EBC.

Our second goal was to characterize the constituents of EBC using an untargeted metabolomics approach. We further determined the effect of saliva contamination on small molecules detection in EBC. The 77 small molecules that were detected in the clean-EBC and the saliva-EBC were undetected in the saliva samples; this suggests that these compounds may be specific to EBC. The 40 out of 77 that were database annotated using Human Metabolome Database (HMDB) [42] and the Kyoto Encyclopedia and Genes and Genomes (KEGG) [43] included the following: vitamin D metabolites, lipids, herbs, spices, food, plants, insecticides, herbicides, dipeptides, and $\mathrm{PAH}$ degradants. Five out of fourteen food metabolites were related to citrus fruit or tea, three were herbs and spices, and the remaining were vegetables, food flavorings, or oils. This is consistent with participants' reports of drinking green tea, coffee, and chocolate milk, and eating pumpkin cake, green beans, club sandwich, and potato chips. Note that participants were not allowed to eat or drink at least two hours prior to sample collection. Other matches for two insecticides and three herbicides were also plausible since these samples were collected when subjects may have applied insect repellants such as diethyltoluamide (DEET) to their skin, and institutions were applying herbicides and pesticides to their lawns. For example, $\mathrm{N}$-cyclopropylammelide is a degradation product of atrazine. Atrazine is an herbicide used to prevent weeds on golf courses and residential lawns.

Other metabolites found in EBC were tentatively identified as endogenous compounds; for example, 3oxooctanoic acid is an endogenous keto acid involved in fatty acid biosynthesis. It is formed by the action of acid synthases from acetyl-CoA and malonyl-CoA precursors. $\mathrm{PE}(44: 7)$ is an endogenous glycerophospholipid associated with cell signaling and membrane integrity and also serves as an energy source [42]. Ganglioside $\mathrm{GM}_{3}$ (d18:0/20:0) is an endogenous sphingolipid. Gangliosides, including $\mathrm{GM}_{3}$ and $\mathrm{GM}_{2}$, have been shown to be downregulated in the hyper-reactive lung and trachea compared to the normal lung and trachea in a guinea pig model of bronchial asthma [44]. Gangliosides have also been shown to be inversely associated with severe emphysema in COPD human plasma [45]. Dipeptides were also annotated. These included glutamyl-glycine, methionyl-arginine, tyrosyl-histidine, and phenylalanyl-histidine. Dipeptides are incomplete breakdown products of protein digestion or protein catabolism. Many dipeptides are short-lived intermediates toward specific amino acid degradation pathways while others have physiological [46] or cell-signaling effects [42].

3,4-dihydroxyfluorene is a polycyclic aromatic hydrocarbon (PAH) degradation metabolite. PAH's have been associated with childhood asthma [47] and are found in oil, coal, and tar. They are the result of combustion in engines, and incinerators; sources include forest fires, vehicle exhaust, grilling or barbecuing meat, and smoked fish [48-50]. Lastly, there were two annotated vitamin D metabolites (25-hydroxyvitamin $\mathrm{D}_{2}$-25-glucuronide and 3-deoxy-3-azido-25-hydroxyvitamin $\mathrm{D}_{3}$ ). Vitamin $\mathrm{D}$ and its metabolites are associated with asthma [51, 52] and vitamin $\mathrm{D}$ deficiency has been shown to be a risk factor for developing asthma [53, 54]. Because these compounds have previously reported associations with lung disease, they could either be used as diagnostic markers of health or disease state, or may be novel molecules requiring further interrogation.

Due to low sample volumes, tandem mass spectrometry was only performed in negative mode and resulted in six spectral library matches corresponding to acetylsalicylic acid, 4-chloro-L-phenylalanine, 3,4-furandicarboxylic acid, 
shikimic acid, succinic acid, and citric acid (Additional file 5). With additional sample, targeted MSMS can be performed on additional EBC metabolites to further explore their identities. Other metabolites present may be below our limit of detection or require more specialized sample preparation techniques. Therefore, detection of specific molecules or classes, may require derivatization, solid phase extraction, or enzymatic techniques, as described by Chérot-Kornobis et al [17] for nitrogen oxides, Esther Jr. et al [55] for purines, or Rossi et al [56] for glutathione.

A major objective of the current study was to determine if eicosanoid detection in $\mathrm{EBC}$ was the result of saliva contamination. With the exception of one molecule in one subject, we were unable to detect eicosanoids in EBC of over 100 asthmatic subjects, a group in which higher concentrations of these molecules have been reported (Fig. 4). Our EBC sample preparation step included diluting the EBC volume to $1 \mathrm{~mL}$; this may have diluted levels to below the limit of detection for the targeted eicosanoid panel. However, the concentration of eicosanoids ranged from 10-fold to 100-fold lower in EBC compared to saliva from matched asthmatic subjects (Fig. 4). Since our sample preparation methods, including low starting volumes, were consistent with previous investigations reporting the detection of eicosanoids in EBC, this suggests that previously reported values could possibly be due to salivary contamination. This is further supported by the detection of some eicosanoids when a very highly concentrated $(13 \mathrm{ml})$ EBC sample is used. Within the asthmatic saliva samples, the concentrations varied in the range 58-187\% $\mathrm{CV}$ for the samples with detectable levels of eicosanoids. These results show that eicosanoid concentrations in saliva vary widely amongst asthmatic subjects.

Due to the poor detection of eicosanoids in EBC using targeted analysis and low starting volumes, we investigated whether any other small molecules could be detected in EBC when larger starting volumes are used. Leftover EBC from asthmatic subjects $(n=107)$ was pooled into a $13 \mathrm{~mL}$ aliquot, lyophilized, and reconstituted in $20 \mu \mathrm{L}$ of HPLC buffer. Untargeted LC-MS revealed 97 metabolites, of which four were eicosanoid derivatives: $\mathrm{LTE}_{3}$, thromb-

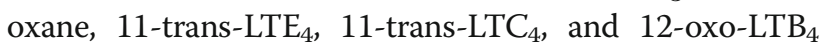
(Additional file 6). Results suggest that although eicosanoid metabolites are present in $\mathrm{EBC}$, samples require a drastic pre-concentration step prior to LC-MS analysis in order for these molecules to be detected. In addition, some of these detected metabolites may be breakdown products of the deuterated standards spiked during sample preparation, particularly during the lyophilization step.

In a few studies, investigators increased the amount of EBC used to $1 \mathrm{~mL}$ and obtained detectable metabolite signal. For example, Pelclová et al [11] collected EBC over 15-20 min using the ECoScreen. They analyzed
EBC of 82 patients with occupational lung diseases \& 27 controls were analyzed using SPE followed by LC-ESIMS/MS. Results showed elevation of $\mathrm{LTB}_{4}, \mathrm{LTC}_{4}$, and $\mathrm{LTE}_{4}$ in asbestos-exposed and silica-exposed patients compared to controls. Conventz et al [19] collected 1-6 mL EBC from 27 healthy adults also using the ECoScreen. $1 \mathrm{~mL} E B C$ was used to quantify proline, hydroxyproline, and tyrosine using LC-ESI-MS/MS. Fritscher et al [6] collected at least $1 \mathrm{~mL}$ of EBC from 87 subjects for over $10 \mathrm{~min}$ and performed targeted analysis on a QQQ-MS. They examined twenty-three eicosanoids in the EBC from asthma and COPD individuals, five of which overlapped with our study. Our study examined an additional eleven molecules that were not present in their study.

A major difference between our study and others is that our aim was specifically to determine the potential for and extent of saliva contamination in EBC sampling. Therefore, our studies incorporated a well-controlled set of experiments that included mimicking EBC collection. Overall, we required greater than $1 \mathrm{~mL}$ EBC for detection of eicosanoids; preparation included concentrating samples in a lyophilizer. Other investigators have also concentrated their EBC samples prior to analysis. Montuschi et al [57] collected $1.5 \mathrm{~mL}$ EBC per subject over 15 min using the ECoScreen and concentrated the EBC 40-fold. $20 \mu \mathrm{L}$ of sample was injected and analyzed for $\mathrm{LTB}_{4}$ using LC-MS \& LC-MS/MS.

Our methods were replicated in an independent cohort. EBC was collected from 13 volunteers and grouped in four categories based on health and smoking status: healthy non-smoker, healthy smoker, non-smoker with common cold, and non-smoker with nasal congestion. Saliva contamination was not present, as measured by a proteomic approach. Using untargeted LC-MS metabolomics, 172 metabolites were detected in EBC, 81 of which were present in all 4 sample groups (Fig. 5a). Fold changes were observed (Fig. 5b) but no statistical inferences could be made. Qualitatively however, the healthy EBC contained fewer compounds compared to the EBC of subjects with nasal congestion, the common cold, or the smoker (Fig. 5a). This may be due to differences in diet, or because subjects with signs of illness may ingest cold, flu, or nasal decongestion medication which may artificially increase the number of detected compounds in their $\mathrm{EBC}$.

Some of the detected metabolites in the smoker, healthy, common cold, and nasal congestion EBC (Table 3 and Additional file 7) were markers of environmental exposure such as 1-hydroxy-2-naphthoic acid which is a PAH and naphthalene degradation metabolite. This metabolite also mapped to the "degradation of aromatic compounds" pathway, as did 6-hydroxy caproic acid and p-cymene. Ephedrine, used as a decongestant, was only detected in the common cold group. Additional detected metabolites 
such as 2-Oxo-4-hydroxy-5-aminovalerate, homoserine, arogenate, tetrahydrodipicolinate, and 2-amino-3,7dideoxy-D-threo-hept-6-ulosonic acid play roles in amino acid metabolism and/or biosynthesis [58]. Many of these compounds were absent in the healthy EBC but were present in the EBC of individuals who smoked, had nasal congestion, or had the common cold. Other detected metabolites were part of purine metabolism [ureidoglycine], sphingolipid signaling pathway [C14 sphingosine], glycerolipid metabolism [PA(22:2), MG(18:1)], and glycerophospholipid metabolism [PC(40:7), PG(38:8), PA(22:2), $\mathrm{PI}(24: 0)]$. The lipid compounds $\mathrm{PA}(22: 2)$ and $\mathrm{PI}(24: 0)$ were undetected in the healthy EBC but were detected in the other three groups. These biological pathways have been implicated in lung diseases such as asthma [59] and COPD $[45,60]$.

Targeted eicosanoid analysis was also performed on the healthy, smoker, common cold, and nasal congestion EBC. Nineteen eicosanoids were detected in the smoker EBC which were undetected in the other groups. Elevated levels of 13-HODE, 13-OxoODE, 9-HODE, and 9-OxoODE were observed in both the smoker and nasal congestion EBC compared to the healthy and common cold EBC. This increase in eicosanoids in smoking samples has been observed in previous studies. Sanak et al [61] analyzed EBC from 17 healthy smokers and 41 healthy non-smokers collected using the ECoScreen. Results showed an increase in 5-HETE and 8 -iso-PGF $2 \alpha$ in the current smokers compared to the non-smokers. We conclude that cigarette smoking increases the inflammatory and oxidative stress markers observed in our study to levels that were at least 3-fold higher compared to the healthy EBC.

Proteomics analysis of these four groups detected few proteins in the EBC samples using both human and bacterial searches (Table 4). In a review in 2014, Harshman et al. [18] summarized 80 detected proteins in EBC from the current literature including one detected in our study. Although no proteins were detected in our nasal congestion or common cold EBC samples, keratin type I cytoskeleton 9 (Cytokeratin-9) was detected in healthy EBC. Cytokeratin-9 has been previously been identified in asthmatic EBC [62], and in the pooled EBC of nonsmokers and healthy smokers [63]. However, others have suggested that cytokeratin in EBC is the result of ambient air rather than the airways [64]. We detected zinc finger protein 800 and myoneurin in the smoker EBC. Zinc finger protein 800 and myoneurin (also a zinc finger protein) have not been previously reported in EBC. Other zinc finger proteins have been detected; zinc finger $\mathrm{CCCH}$ domain-containing protein 4 ( $\mathrm{ZC} 3 \mathrm{H} 4)$ has been reported in healthy non-smoker and healthy smoker EBC [63]. In our study, no salivary proteins were detected, indicating that the EBC samples from the replication study were not contaminated with saliva. A larger, more diverse cohort encompassing multiple lung diseases may be required to explore the diversity of exhaled proteins.

This study is particularly significant to EBC researchers because it emphasizes the issues of compound adsorption, saliva contamination, and high volumes of $\mathrm{EBC}$ required for biomarker discovery studies. The strengths of this study lie in the precise methods used and the large sample size of Cohort 2 in the asthmatic study. We recognize that some limitations exist. First, the sample number is limited for Cohorts 1 and 3. Second, subjects in these cohorts only refrained from food intake for 2-3 h rather than $12 \mathrm{~h}$, which could explain some differences in metabolites detected. Lastly, due to limited sample volumes, additional analyses could not be performed to compare the three cohorts across all mass spectrometry technologies. Future studies could be aimed at rectifying these limitations.

\section{Conclusions}

We conclude that measureable levels of small molecules, including amino acids and eicosanoids, are present in healthy EBC; however, the dilute nature of $\mathrm{EBC}$ requires larger volumes of starting material than currently reported in the literature. We suggest the collection of at least $15 \mathrm{~mL}$ of $\mathrm{EBC}$ per subject and pre-concentrating by at least 20 -fold to as much as 500 -fold prior to LC-MS analysis in order to confidently and reproducibly detect metabolites of interest. Secondly, although $\alpha$-amylase assays can test for the presence of saliva in EBC, small volumes of saliva may still be present but be below the detection limits of the assay. Since saliva can be responsible for contaminating EBC samples, proper sample collection and handling is necessary, particularly the use of a saliva trap during sample collection. Thirdly, eicosanoid concentrations in saliva vary widely amongst asthmatic subjects and this should be considered when designing experiments. Here, we provide a general presentation of EBC constituents from which investigators can probe more specialized techniques to detect additional or lower abundant compounds of interest. These results suggest that large volumes of samples and a more targeted approach are needed when using EBC to study asthma and other lung diseases.

\section{Additional files}

Additional file 1: Targeted mass spectrometry parameters for eicosanoid analysis. MRM parameters, retention times, associated internal standards, and ionization modes used for lipid mediators by LC-MS/MS. IS: internal standard. (PDF $23 \mathrm{~kb}$ )

Additional file 2: Peak areas of selected amino acids and eicosanoids detected in EBC and/or saliva samples. (A) Peak areas of selected eicosanoids using untargeted metabolomics; (B) Peak areas of selected amino acids in spiked water (green), clean-EBC (black), saliva-EBC (blue), and saliva (red) using untargeted metabolomics. A control water sample 
which was spiked with known concentrations of amino acids and eicosanoids was used to confirm the identities of these compounds in the saliva and EBC samples using exact mass, isotope ratios and retention time. (C) Peak area of $\mathrm{LTB}_{4}$ in internal standard, EBC and saliva using targeted analysis. (D) Peak area of $\mathrm{LTE}_{4}$ in internal standard and EBC using targeted analysis. Peak areas were extracted using MassHunter Quantitative Analysis software (Agilent). y-axis: mass spectral counts; $x$-axis: retention time. Starting volumes for untargeted metabolomics was $11.5 \mathrm{~mL}$ (clean-EBC) and $7.5 \mathrm{~mL}$ (saliva-EBC) with final volume of $20 \mu \mathrm{L}$ and injection volume of $5 \mu \mathrm{L}$. Starting volume for targeted analysis was $1 \mathrm{~mL}$ saliva or EBC with an injection volume of $100 \mu \mathrm{L}$. (TIF $1669 \mathrm{~kb}$ )

Additional file 3: Separation of $\mathrm{PGF}_{2 \mathrm{a}}$ isomers in spiked control water Samples were injected onto an SB-AQ analytical column. Since the four isomers could not be differentiated using untargeted analysis, multiple reaction monitoring (MRM) using a triple quadrupole mass spectrometer (QQQ-MS) with a C18 column was used to determine their elution order. (TIF $710 \mathrm{~kb}$ )

Additional file 4: Molecular formula annotated metabolites and unannotated metabolites detected in exhaled breath condensate (EBC). These 37 out of 77 unique compounds were not matched to a database compound. Samples were analyzed in positive and negative ionization mode using LC-MS untargeted metabolomics on an SB-AQ analytical column. + indicates detected in positive ionization mode, - indicates detected in negative ionization mode. (PDF $38 \mathrm{~kb}$ )

Additional file 5: Tandem MS fragmentation patterns for six EBC metabolites. The mass spectral fragment peaks in red indicate the experimental results. The peaks in blue indicate the database matches based on standards. (PDF $36 \mathrm{~kb}$ )

Additional file 6: Putatively identified eicosanoids in EBC. $13 \mathrm{~mL}$ of pooled EBC from 107 asthmatic subjects was lyophilized, reconstituted in $20 \mu \mathrm{L}$ of buffer, and analyzed using LC-MS based metabolomics. Metabolite peaks were extracted using Profinder and MassHunter software using exact mass and isotope ratios (Agilent). Detected peaks are indicated by single colored lines. Database isotope pattern and distribution is indicated by a circled red box. Matches with multiple adducts are indicated. (PDF $55 \mathrm{~kb}$ )

Additional file 7: Metabolite annotations and tandem MS fragmentation patterns of compound detected in EBC. EBC was collected from four groups of volunteers: healthy smokers, healthy non-smokers, non-smokers with nasal congestion, and non-smokers with the common cold. Samples were pooled, lyophilized, reconstituted in $20 \mu \mathrm{L}$ of buffer, and analyzed using LC-MS based metabolomics. Metabolite peaks were extracted with Mass Hunter Profinder software (Agilent) using exact mass and isotope ratios. Tandem MS was performed, spectra was exported to NIST MS Search v2.2, and matched to the NIST14 Mass Spectral library. Fragments in red indicate EBC sample, fragments in blue indicate NIST standard reference spectra. (PDF $545 \mathrm{~kb}$ )

Additional file 8: Targeted eicosanoid analysis of $E B C$. $E B C$ was collected from four groups of volunteers: healthy smokers, healthy nonsmokers, non-smokers with nasal congestion, and non-smokers with the common cold. Samples were pooled, lyophilized, reconstituted in LC-MS buffer, and analyzed using targeted LC-MS on a triple quadruple mass spectrometer. (PDF $40 \mathrm{~kb}$ )

Additional file 9: Pathway analysis based on sample type. The compounds which were detected in each sample type were mapped to KEGG pathways using the online freeware pathway analysis software MBROLE. The compound names were based on database annotations using exact mass, isotope ratios and/or MSMS. Only pathways with hits $\geq 2$ are listed. (PDF $278 \mathrm{~kb}$ )

\section{Abbreviations}

$11 \beta-P G F_{2 a}: 11$ beta-prostaglandin $F_{2}$ alpha; 15R-PGF $2 a: 15 R$-prostaglandin $F_{2}$ alpha; 8-iso-PGF $2 \mathrm{a}$ : 8-isoprostane-prostaglandin $\mathrm{F}_{2}$ alpha; APCl: Atmospheric pressure chemical ionization; BAL: Bronchoalveolar lavage; C18: Reverse phase chromatography with octadecyl carbon chain (C18)-bonded silica; CE: Collision energy; COPD: Chronic obstructive pulmonary disease; CysLT: Cysteinyl-leukotrienes; DiHDoHE: Dihydroxy-docosahexaenoic acid; EBC: Exhaled breath condensate; EIA: Enzyme immunoassay; ESI: Electrospray ionization; HDHA: Hydroxy-docosahexaenoic acid; HETE: Hydroxy- eicosatetraenoic acid; HILIC: Hydrophilic interaction chromatography; HMDB: Human metabolome database; KEGG: Kyoto encyclopedia of genes and genomes; LC: Liquid chromatography; LC-MS: Liquid chromatography mass spectrometry; LC-MS/MS: Liquid chromatography tandem mass spectrometry; LOD: Limit of detection; LOQ: Limit of quantitation; LTB 4 : Leukotriene $B_{4}$; LTC $_{4}$ : Leukotriene $C_{4}$; LTD $_{4}$ : Leukotriene $D_{4}$;

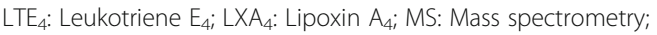
MSMS: Tandem mass spectrometry; $\mathrm{PGE}_{2}$ : Prostaglandin $\mathrm{E}_{2}$; PGF2a: Prostaglandin $\mathrm{F}_{2}$ alpha; Protectin DX: 10(S),17(S)-DiHDoHE; QQQ: Triple quadrupole; Q-TOF: Quadrupole time-of-flight; RvD1: Resolvin D1; $\mathrm{R}_{\mathrm{V}} \mathrm{D2}$ : Resolvin D2; SB-AQ: Stable bond (diisopropyl side chain group); SRM: Selected reaction monitoring; $\mathrm{TXB}_{2}$ : Thromboxane $\mathrm{B}_{2}$

\section{Acknowledgements}

Not applicable.

\section{Funding}

This publication was supported by NIH-NCRR grant 1S100D010366-01A1 to N.R. and NIH/NCATS Colorado CTSA Grant Number UL1 TR001082. Its contents are the authors' sole responsibility and do not necessarily represent official $\mathrm{NIH}$ views.

\section{Availability of data and materials}

The datasets supporting the conclusions of this article are included within the article and its additional files.

\section{Authors' contributions}

$\mathrm{NR}, \mathrm{MLA}$, and CCQ conceived and designed the experiments; CCQ, MLA, RP, and JG performed the experiments; CCQ, MLA, RP, and JG analyzed the data; CCQ wrote the manuscript; NR and ME edited the manuscript; all authors reviewed and approved the final manuscript.

\section{Competing interests}

The authors declare that they have no competing interests.

\section{Consent for publication}

Not applicable.

\section{Ethics approval and consent to participate}

Studies were approved by the Western Institutional Review Board or National Jewish Health IRB. All participants gave informed consent prior to the start of the study.

\section{Publisher's Note}

Springer Nature remains neutral with regard to jurisdictional claims in published maps and institutional affiliations.

\section{Received: 3 November 2016 Accepted: 18 March 2017} Published online: 12 April 2017

\section{References}

1. Marteus H, Törnberg D, Weitzberg E, Schedin U, Alving K. Origin of nitrite and nitrate in nasal and exhaled breath condensate and relation to nitric oxide formation. Thorax. 2005;60(3):219-25. doi:10.1136/thx.2004.030635.

2. Brzozowska A, Majak P, Jerzyńska J, Smejda K, Bobrowska-Korzeniowska M, Stelmach W, et al. Exhaled nitric oxide correlates with IL-2, MCP-1, PDGF-BB and TIMP-2 in exhaled breath condensate of children with refractory asthma. Adv Dermatol Allergol. 2015;32(2):107-13. doi:10.5114/pdia.2014.40953.

3. Carraro S, Giordano G, Piacentini G, Kantar A, Moser S, Cesca L, et al. Asymmetric dimethylarginine in exhaled breath condensate and serum of children with asthma. Chest. 2013;144(2):405-10. doi:10.1378/chest.12-2379.

4. Esther Jr CR, Boysen G, Olsen BM, Collins LB, Ghio AJ, Swenberg JW, et al. Mass spectrometric analysis of biomarkers and dilution markers in exhaled breath condensate reveals elevated purines in asthma and cystic fibrosis. Am J Physiol Lung Cell Mol Physiol. 2009;296(6):L987-L93. doi:10.1152/ ajplung.90512.2008.

5. Corradi M, Pesci A, Casana R, Alinovi R, Goldoni M, Vettori MV, et al. Nitrate in exhaled breath condensate of patients with different airway diseases. Nitric Oxide. 2003;8(1):26-30. doi:10.1016/\$1089-8603(02)00128-3. 
6. Fritscher LG, Post M, Rodrigues MT, Silverman F, Balter M, Chapman KR, et al. Profile of eicosanoids in breath condensate in asthma and COPD. J Breath Res. 2012;6(2):026001. doi:10.1088/1752-7155/6/2/026001.

7. Esther Jr CR, Lazaar AL, Bordonali E, Qaqish B, Boucher RC. Elevated airway purines in COPD. Chest. 2011;140(4):954-60.

8. Borrill ZL, Roy K, Singh D. Exhaled breath condensate biomarkers in COPD Eur Respir J. 2008;32(2):472-86. doi:10.1183/09031936.00116107.

9. Esther Jr CR, Olsen BM, Lin FC, Fine J, Boucher RC. Exhaled breath condensate adenosine tracks lung function changes in cystic fibrosis. Am J Physiol Lung Cell Mol Physiol. 2013;304:1504-9. doi:10.1152/ ajplung.00344.2012.

10. Monge ME, Pérez JJ, Dwivedi P, Zhou M, McCarty NA, Stecenko AA, et al. Ion mobility and liquid chromatography/mass spectrometry strategies for exhaled breath condensate glucose quantitation in cystic fibrosis studies. Rapid Commun Mass Spectrom. 2013:27(20):2263-71. doi:10.1002/rcm.6683

11. Pelclová D, Fenclová Z, VIcková S, Lebedová J, Syslová K, Pecha O, et al. Leukotrienes B4, C4, D4 and E4 in the exhaled breath condensate (EBC), blood and urine in patients with pneumoconiosis. Ind Health. 2012;50(4):299-306.

12. Barnes PJ. The cytokine network in asthma and chronic obstructive pulmonary disease. J Clin Invest. 2008;118(11):3546-56. doi:10.1172/JCl36130.

13. De Rose V, Trentin L, Crivellari MT, Cipriani A, Grassi GG, Pozzi E, et al. Release of prostaglandin E2 and leukotriene B4 by alveolar macrophages from patients with sarcoidosis. Thorax. 1997;52(1):76-83. doi:10.1136/thx.52.1.76.

14. Samitas K, Chorianopoulos D, Vittorakis S, Zervas E, Economidou E, Papatheodorou G, et al. Exhaled cysteinyl-leukotrienes and 8-isoprostane in patients with asthma and their relation to clinical severity. Respir Res. 2009; 103(5):750-6. doi:10.1016/j.rmed.2008.11.009.

15. Antczak A, Ciebiada M, Pietras T, Piotrowski WJ, Kurmanowska Z, Górski P. Exhaled eicosanoids and biomarkers of oxidative stress in exacerbation of chronic obstructive pulmonary disease. Arch Med Sci. 2012;8(2):277-85.

16. Svedahl SR, Svendsen K, Tufvesson E, Romundstad PR, Sjaastad AK, Qvenild T, et al. Inflammatory markers in blood and exhaled air after short-term exposure to cooking fumes. Ann Occup Hyg. 2013;57(2):230-9. doi:10.1093/annhyg/mes069.

17. Chérot-Kornobis N, Hulo S, Edmé JL, de Broucker V, Matran R, Sobaszek A. Analysis of nitrogen oxides (NOX) in the exhaled breath condensate (EBC) of subjects with asthma as a complement to exhaled nitric oxide (FeNO) measurements: a cross-sectional study. BMC Res Notes. 2011;16(4):202. doi:10.1186/1756-0500-4-202.

18. Harshman SW, Grigsby CC, Ott DK. Exhaled breath condensate for proteomic biomarker discovery. Chromatography. 2014;1(3):108-19. doi:10.3390/ chromatography 1030108 .

19. Conventz A, Musiol A, Brodowsky C, Müller-Lux A, Dewes P, Kraus T, et al. Simultaneous determination of 3-nitrotyrosine, tyrosine, hydroxyproline and proline in exhaled breath condensate by hydrophilic interaction liquid chromatography/electrospray ionization tandem mass spectrometry. J Chromatogr B. 2007;860(1):78-85. doi:10.1016/j.jchromb.2007.10.031.

20. Førli L, Pedersen J, Bjørtuft $\varnothing$, Vatn M, Kofstad J, Boe J. Serum amino acids in relation to nutritional status, lung function and energy intake in patients with advanced pulmonary disease. Respir Med. 2000;94(9):868-74 doi:10.1053/rmed.2000.0830

21. Engelen MPKJ, Schols AMWJ. Altered amino acid metabolism in chronic obstructive pulmonary disease: new therapeutic perspective? Curr Opin Clin Nutr Metab Care. 2003;6(1):73-8. doi:10.1097/01.mco.0000049043.06038.fe.

22. Ubhi BK, Cheng KK, Dong J, Janowitz T, Jodrell D, Tal-Singer R, et al. Targeted metabolomics identifies perturbations in amino acid metabolism that sub-classify patients with COPD. Mol BioSyst. 2012;8(12):3125-33.

23. Luykx JJ, Bakker SC, van Boxmeer L, Vinkers CH, Smeenk HE, Visser WF, et al. D-Amino acid aberrations in cerebrospinal fluid and plasma of smokers. Neuropsychopharmacology. 2013;38(10):2019-26. doi:10.1038/npp.2013.103.

24. Ono E, Mita H, Taniguchi M, Higashi N, Tsuburai T, Miyazakiw E, et al. Comparison of cysteinyl leukotriene concentrations between exhaled breathcondensate and bronchoalveolar lavage fluid. Clin Exp Allergy. 2008; 38(12):1866-74. doi:10.1111/j.1365-2222.2008.03108.x

25. Gaber F, Acevedo F, Delin I, Sundblad B-M, Palmberg L, Larsson K, et al. Saliva is one likely source of leukotriene B4 in exhaled breath condensate. Eur Respir J. 2006;28(6):1229-35.

26. Bessonneau V, Bojko B, Pawliszyn J. Analysis of human saliva metabolome by direct immersion solid-phase microextraction LC and benchtop orbitrap MS. Bioanalysis. 2013;5(7):783-92.
27. Dame ZT, Aziat F, Mandal R, Krishnamurthy R, Bouatra S, Borzouie S, et al. The human saliva metabolome. Metabolomics. 2015;11:1864-83. doi:10.1007/s11306-015-0840-5.

28. Carter SR, Davis CS, Kovacs EJ. Exhaled breath condensate collection in the mechanically ventilated patient. Respir Med. 2012;106(5):601-13. doi:10.1016/j.rmed.2012.02.003.

29. Syslová K, Kačer P, Vilhanová B, Kuzma M, Lipovová P, Fenclová Z, et al. Determination of cysteinyl leukotrienes in exhaled breath condensate: method combining immunoseparation with LC-ESI-MS/MS. J Chromatogr B. 2011;879(23):2220-8.

30. Horváth I, Hunt J, Barnes PJ, Alving K, Antczak A, Baraldi E, et al. Exhaled breath condensate: methodological recommendations and unresolved questions. Eur Respir J. 2005:26(3):523-48. doi:10.1183/09031936.05.00029705.

31. Stein S. NIST MS Search Program. 2011. http://chemdata.nist.gov/dokuwiki/ doku.php?id=chemdata:ms-search. Accessed 8 June 2016.

32. NIST/EPA/NIH Mass Spectral Library with Search Program (Data Version: NIST 14, Software Version 2.2 g). 2014. http://www.nist.gov/srd/nist1a.cfm. Accessed 27 Feb 2016.

33. Stein SE. Estimating probabilities of correct identification from results of mass spectral library searches. J Am Soc Mass Spectrom. 1994;5(4):316-23. doi:10.1016/1044-0305(94)85022-4.

34. Kuc S, Koster MPH, Pennings JLA, Hankemeier T, Berger R, Harms AC, et al. Metabolomics profiling for identification of novel potential markers in early prediction of preeclampsia. PLoS One. 2014;9(5):e98540. doi:10.1371/journal. pone.0098540.

35. Harrington C, Reen FJ, Mooij MJ, Stewart FA, Chabot J-B, Guerra AF, et al. Characterisation of non-autoinducing Tropodithietic Acid (TDA) production from marine sponge pseudovibrio species. Mar Drugs. 2012;12(12):5960-78. doi:10.3390/md12125960.

36. Soyer OU, Dizdar EA, Keskin O, Lilly C, Kalayci O. Comparison of two methods for exhaled breath condensate collection. Allergy. 2006;61(8):1016-8. doi:10.1111/j.1398-9995.2006.01064.x.

37. Montuschi P, Kharitonov SA, Ciabattoni G, Barnes PJ. Exhaled leukotrienes and prostaglandins in COPD. Thorax. 2013;58(7):585-8.

38. Piotrowski WJ, Antczak A, Marczak J, Nawrocka A, Kurmanowska Z, Górski P. Eicosanoids in exhaled breath condensate and BAL fluid of patients with sarcoidosis. Chest. 2007;132(2):589-96

39. Effros RM, Biller J, Foss B, Hoagland K, Dunning MB, Castillo D, et al. A simple method for estimating respiratory solute dilution in exhaled breath condensates. Am J Respir Crit Care Med. 2003;168(12):1500-5.

40. Folesani G, Corradi M, Goldoni M, Manini P, Acampa O, Andreoli R, et al. Urea in exhaled breath condensate of uraemics and patients with chronic airway diseases. Acta bio-medica: Atenei Parmensis. 2008;79(Supplemental 1):79-86.

41. Dwyer TM. Sampling airway surface liquid: non-volatiles in the exhaled breath condensate. Lung. 2004;182(4):241-50.

42. Wishart DS, Jewison T, Guo AC, Wilson M, Knox C, Liu Y, et al. HMDB 3.0The human metabolome database in 2013. Nucleic Acids Res. 2013; 41(Database issue):D801-7

43. Kanehisa M, Goto S, Sato Y, Furumichi M, Tanabe M. KEGG for integration and interpretation of large-scale molecular data sets. Nucleic Acids Res. 2012;40(Database Issue):D109-D14. doi:10.1093/nar/gkr988.

44. Banerjee DK. Bronchial hyperreactivity associated with tracheal gangliosides. Science. 1982:218(4572):569-71. doi:10.1126/science.7123258.

45. Bowler RP, Jacobson S, Cruickshank C, Hughes G, Siska C, Ory DS, et al. Plasma sphingolipids associated with chronic obstructive pulmonary disease phenotypes. Am J Respir Crit Care Med. 2015;191(3):275-84. doi:10.1164/rccm.201410-17710C

46. Hashimoto T, Perlot $T$, Rehman A, Trichereau J, Ishiguro H, Paolino M, et al. ACE2 links amino acid malnutrition to microbial ecology and intestinal inflammation. Nature. 2012;487(7408):477-81. doi:10.1038/nature11228.

47. Al-Daghri NM, Alokail MS, Abd-Alrahman SH, Draz HM, Yakout SM, Clerici M. Polycyclic aromatic hydrocarbon exposure and pediatric asthma in children: a case-control study. Environ Health. 2013;12(1). doi:10.1186/1476-069X-12-1.

48. Gomaa EA, Gray Jl, Rabie S, Lopez-Bote C, Booren AM. Polycyclic aromatic hydrocarbons in smoked food products and commercial liquid smoke flavourings. Food Addit Contam. 1993;10(5):503-21.

49. Larsson BK, Sahlberg GP, Eriksson AT, Busk LA. Polycyclic aromatic hydrocarbons in grilled food. J Agric Food Chem. 1983;31(4):867-73. doi:10.1021/jf00118a049.

50. Srogi K. Monitoring of environmental exposure to polycyclic aromatic hydrocarbons: a review. Environ Chem Lett. 2007;5(4):169-95. 
51. Huang H, Porpodis K, Zarogoulidis P, Domvri K, Giouleka P, Papaiwannou A, et al. Vitamin D in asthma and future perspectives. Drug Des Devel Ther. 2013;7:1003-13. doi:10.2147/DDDT.S50599.

52. Kho AT, Sharma S, Qiu W, Gaedigk R, Klanderman B, Niu S, et al. Vitamin D related genes in lung development and asthma pathogenesis. BMC Med Genom. 2013;6:47. doi:10.1186/1755-8794-6-47.

53. Paul G, Brehm JM, Alcorn JF, Holguín F, Aujla SJ, Celedón JC. Vitamin D and Asthma. Am J Respir Crit Care Med. 2012;185(2):124-32. doi:10.1164/rccm. 201108-1502Cl.

54. Litonjua AA, Vitamin D. Deficiency as a risk factor for childhood allergic disease and asthma. Curr Opin Allergy Clin Immunol. 2012;12(2):179-85. doi:10.1097/ACl.0b013e3283507927.

55. Esther Jr CR, Alexis N, Clas ML, Lazarowski ER, Donaldson SH, Ribeiro CM, et al. Extracellular purines are biomarkers of neutrophilic airway inflammation. Eur Respir J. 2008:31(5):949-56. doi:10.1183/09031936.0008980.

56. Rossi R, Milzani A, Dalle-Donne I, Giustarini D, Lusini L, Colombo R, et al. Blood glutathione disulfide: in vivo factor or in vitro artifact? Clin Chem. 2002;48(5):742-53

57. Montuschi P, Martello S, Felli M, Mondino C, Chiarotti M. Ion trap liquid chromatography/tandem mass spectrometry analysis of leukotriene B4 in exhaled breath condensate. Rapid Commun Mass Spectrom. 2004;18(22): 2723-9. doi:10.1002/rcm.1682.

58. Kanehisa M, Goto S. KEGG: Kyoto encyclopedia of genes and genomes. Nucleic Acids Res. 2000;28(1):27-30

59. Yu M, Cui FX, Jia HM, Zhou C, Yang Y, Zhang HW, et al. Aberrant purine metabolism in allergic asthma revealed by plasma metabolomics. J Pharm Biomed Anal. 2016;120:181-9. doi:10.1016/j.jpba.2015.12.018.

60. t'Kindt R, Telenga ED, Jorge L, Van Oosterhout AJM, Sandra P, Ten Hacken NHT, et al. Profiling over 1500 Lipids in Induced Lung Sputum and the Implications in Studying Lung Diseases. Anal Chem. 2015;87(9):4957-64. doi:10.1021/acs.analchem.5b00732.

61. Sanak M, Gielicz A, Nagraba K, Kaszuba M, Kumik J, Szczeklik A. Targeted eicosanoids lipidomics of exhaled breath condensate in healthy subjects. Chromatogr B. 2010;878(21):1796-800. doi:10.1016/j.jchromb.2010.05.012.

62. Bloemen K, Van Den Heuvel R, Govarts E, Hooyberghs J, Nelen V, Witters E, et al. A new approach to study exhaled proteins as potential biomarkers for asthma. Clin Exp Allergy. 2011;41(3):346-56. doi:10.1111/ j.1365-2222.2010.03638.x.

63. Fumagalli M, Ferrari F, Luisetti M, Stolk J, Hiemstra PS, Capuano D, et al. Profiling the proteome of exhaled breath condensate in healthy smokers and COPD patients by LC-MS/MS. Int J Mol Sci. 2012;13(11):13894-910. doi: 10.3390/ijms131113894.

64. Hoffmann HJ, Tabaksblat LM, Enghild JJ, Dah R. Human skin keratins are the major proteins in exhaled breath condensate. Eur Respir J. 2008;31 (2):380-4. doi:10.1183/09031936.00059707.

\section{Submit your next manuscript to BioMed Central and we will help you at every step:}

- We accept pre-submission inquiries

- Our selector tool helps you to find the most relevant journal

- We provide round the clock customer support

- Convenient online submission

- Thorough peer review

- Inclusion in PubMed and all major indexing services

- Maximum visibility for your research

Submit your manuscript at www.biomedcentral.com/submit

C) Biomed Central 